
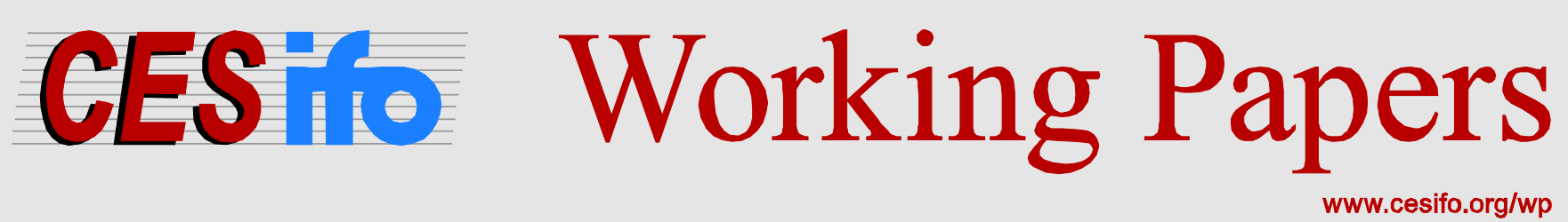

\title{
Why are Firms that Export Cleaner? International Trade and CO2 Emissions
}

\author{
Rikard Forslid \\ Toshihiro Okubo \\ Karen Helene Ulltveit-Moe
}

CESIFO WORKING PAPER NO. 4817

CATEGORY 8: TRADE POLICY

MAY 2014

An electronic version of the paper may be downloaded

- from the SSRN website:

- from the RePEc website:

- from the CESifo website:

WWW.SSRN.com

www.RePEc.org

www.CESifo-group.org/wp

\section{CESifo}




\title{
Why are Firms that Export Cleaner? International Trade and CO2 Emissions
}

\begin{abstract}
This paper develops a model of trade and CO2 emissions with heterogenous firms, where firms make abatement investments and thereby have an impact on their level of emissions. The model shows that investments in abatements are positively related to firm productivity and firm exports. Emission intensity is, however, negatively related to firms. productivity and exports. The basic reason for these results is that a larger production scale supports more investments in abatement and, in turn, lower emissions per output. We show that the overall effect of trade is to reduce emissions. Trade weeds out some of the least productive and dirtiest firms thereby shifting production away from relatively dirty low productive local firms to more productive and cleaner exporters. The overall effect of trade is therefore to reduce emissions. We test empirical implications of the model using unique Swedish firmlevel data. The empirical results support our model.
\end{abstract}

JEL-Code: F120, F140, F180, Q560.

Keywords: heterogeneous firms, CO2-emissions, international trade.

Rikard Forslid
Stockholm University
Stockholm / Sweden
rf@ne.su.se

Karen Helene Ulltveit-Moe

University of Oslo

Oslo / Norway

k.h.ulltveit-moe@econ.uio.no
Toshihiro Okubo

Keio University

Tokyo / Japan

okubo@rieb.kobe-u.ac.jp

This version, May 2014

We are grateful for comments from Andrew Bernard, Peter Egger, Peter Fredriksson, Beata Javorcik, Gordon Hanson, Peter Neary, Scott Taylor, Adrian Wood, and Tony Venables. Financial support from Jan Wallander and Tom Hedelius.Research Foundation, The Swedish Research Council, Grant-in-Aid for Scientific Research (JSPS) and Research Institute of Economy, Trade and Industry (RIETI) is gratefully acknowledged. 


\section{Introduction}

There is no consensus on the effect of international trade on the environment, in particular on the effect of trade on global emissions. Neither the theoretical nor the empirical literature provides a clean cut answer to the link between trade and CO2 emissions. Hence, we do not know if international trade increases or decreases the emissions of greenhouse gases and contributes to global warming. However, this paper sets out explain why we may expect exporter to emit less $\mathrm{CO} 2$, and why trade liberalization may thus lead to cleaner industrial production. We do so by focusing on inter-firm productivity differentials and interdependence among productivity, exporting, abatement and CO2 emissions.

In theoretical neoclassical models, international trade has opposing effects. On the one hand, trade increases income, which will tend to increase the demand for a clean environment and therefore increase investments in clean technology and abatement. On the other hand, trade liberalization may also imply an overall expansion of dirty production, because trade allows countries with low emission standards to become pollution havens. Copeland and Taylor (1995) show how trade liberalization may increase global emissions if the income differences between the liberalizing countries are large, as dirty industries are likely to expand strongly in the poor country with low environmental standards.

The empirical literature that analyses the link between trade in goods and emissions based on sector level data is also inconclusive. ${ }^{1}$ Antweiler et al. (2001) and Frankel and Rose (2005) find that trade decreases emissions. Using U.S. data, Ederington et al. (2004) do not find any evidence that pollution intensive industries have been disproportionately affected by tariff changes. On the other hand, also using sector-level trade data, Levinson and Taylor (2008) find evidence that higher environmental standards in the US have increased the imports from Mexico in dirty industries.

We employ a unique firm level data based on the Swedish Manufacturing Census which do not only provide information on standard firm characteristics like output, value added etc, but also on their international trade as well as CO2 emissions. Based on these data, we start by providing evidence that firms' emissions differ significantly across firms, even within rather narrowly defined industries. Moreover, comparing non-exporters and exporters in Swedish manufacturing, we find that in most manufacturing industries exporters do on average have a lower emission intensity. Motivated by these basic facts we build a theoretical model on international trade and $\mathrm{CO} 2$ emissions where firms are heterogeneous with respect to productivity, abatement investments and emission intensity. We propose and develop a mechanism for why exporters may have a lower emission intensity. This mechanism runs through firms' investments in abatement. According to the theory firms' abatement investments depend on their production volumes, as a larger scale allow them to spread the fixed costs of abatement investment across more units.

\footnotetext{
${ }^{1}$ Early surveys are made by Copeland and Taylor (2004) and Brunnermeier and Levinson (2004).
} 
Production volumes are moreover determined by firms' productivity and export status. More productive firms access international markets, have higher volumes and make higher abatement investments. As a consequence, firms' emission intensity is negatively related to firms' productivity and export status.

Our theoretical model also allows for prediction on the impact of trade liberalization on total $\mathrm{CO} 2$ emissions. We find that total emissions from the manufacturing sector decreases as a result of trade and trade liberalization. Trade affects the exporting and non-exporting sector in different ways. Exporters are - for any level of trade costs - always cleaner than non-exporters, and we show that trade liberalization may make exporters even cleaner by inducing them to invest more in abatement. But trade liberalization also implies higher production volumes for exporters, which c.p. entails higher emissions. Total emissions therefore increases from the exporting sector. However, trade moreover increases local competition, which implies that the least productive, and therefore dirtiest, firms are forced to close down, while the remaining non-exporters are forced to scale down their production volume. Together these different effects of trade liberalization serve as to decrease total emissions from the non-exporting sector. Adding up the effects on exporters and non-exporters we find that trade liberalization will always lead to lower total emissions. Thus, as trade weeds out some of the least productive and dirtiest firms, thereby shifting production away from relatively dirty low productive local firms to more productive and cleaner exporters, the overall effect of trade liberalization is to reduce emissions.

The theoretical model allows us to derive a set of empirical predictions on emissions and exporting as well as abatement investment and exporting. Access to the detailed firm level data set for Swedish manufacturing firms allow us to test these. Our data set contains firm-level emissions and firm-level abatement investments as well as firm exports. According to our model, productivity drives the firm level CO2 emission intensity as well as the export status of a firm. However, while productivity has a continuos effect on the emission intensity, the model predicts a discontinuous jump down in the emission intensity as firms become exporters. The same kind of relationship is predicted for abatement and exporting. We exploit these features of the model as we take the model to the data. The empirical results are strongly supportive of the results derived in the theoretical model; exporters are found to invest more in abatement and to have lower emission intensity.

Our theory is related to the idea presented in Levinson (2009) that trade may contribute to reduced pollution as trade liberalization may encourage technological upgrading. From a more methodological point of view, our work is also related to the literature on heterogeneous firms and trade induced technological upgrading, see e.g. Bas (2012) and Bustos (2012). The majority of empirical analyses of environmental emissions are, unlike our study, based on industry level data. There are, however, a few exceptions, which are thus closer in the spirit to our analysis, see e.g. Holladay (2011), Batrakova 
and Davies (2012), and Rodrigue and Soumonni (2014). Holladay analyses firm-level data for the US, and find that exporters pollute less per output. However, his analysis is based on a sample of firms with large emissions, he studies environmental emissions not CO2 emission and he does not investigate the mechanism for why exporting and emission intensity is related.

The structure of the paper is as follows. In the next section we present a data set on Swedish manufacturing firms and their CO2 emissions. Based on these we develop a set of basic facts on the variation in $\mathrm{CO} 2$ emission intensity across industries and firms, and examine the differences in emission intensity between non-exporters and exporters. We let the descriptive evidence on emissions and how they vary, guide our theoretical model on international trade, $\mathrm{CO} 2$ emissions and heterogeneous firms. We present this model in Section 3, and it allows us to derive a set of propositions and empirical implications regarding $\mathrm{CO} 2$ emissions, abatement and trade. In Section 4 we take the theory to the data, and test the empirical predictions on the relationship between CO2 emissions, export and productivity, and on the relationship between abatement, export and productivity. Finally, Section 5 concludes.

\section{Data and background}

\subsection{Data}

In order to analyze the relationship between trade, emissions and abatement, we use manufacturing census data for Sweden. The census data contains information on the firm level for a large number of variables such as export (tSEK), employment (number of employees), capital stock (tSEK), use of intermediates (tSEK) and value of output (tSEK). Our firm level data cover the period 2000-2011.

Statistics Sweden collect information on the usage of energy from all manufacturing plants with 10 or more employees, and we have access to these for the time period 20042011. The energy statistics include all types of fuel use, from which CO2 emissions $(\mathrm{kg})$ can be calculated by using fuel specific CO2 emissions coefficients provided by Statistics Sweden. CO2 emissions are accurately calculated from fuel inputs since a technology for capturing $\mathrm{CO} 2$ at the pipe is not yet operational. ${ }^{2}$ The calculated plant level emissions are aggregated to the firm level. This provides us with CO2 emission data for around 19500 manufacturing firms for the years 2004-2011, which we match with the census data. ${ }^{3}$

\footnotetext{
${ }^{2} \mathrm{~A}$ few large powerplants are experimenting with capturing $\mathrm{CO} 2$ under ground, but as we are focusing on manufacturing, these are not included in our data.

${ }^{3}$ Note, that as the census provides data for all firms, limiting the the number to firms with at least one employee, we start with a number of 37745 firms for the period 2004-2011. However, due to the fact that energy statistics only are collected for plants with 10 or more employees, this reduces our sample with close to 50 percent.
} 
We also have access to firm level data on abatement over the period 2000-2011. The abatement data is collected based on an annual survey where firms are asked about abatement investments (tSEK) as well as variable abatement costs (tSEK). As for abatement investment the firms are asked to report any investment in machines and equipment specifically aimed at reducing emissions, but also to report expenses related to investment in cleaner machines and technology. In the latter case they are specifically asked to report the extra expenses related to the choice of investing in cleaner relative to less clean machines and technology. The abatement data is based on a semi-random sample of manufacturing firms, and include all manufacturing firms with more than 250 employees, 50 percent of the firms with 100-249 employees, and 20 percent of the firms with 50-99 employees. In total, around 1500 manufacturing firms are surveyed over the time period 2000-2011.

Swedish manufacturing firms face a CO2 tax. Sweden enacted a tax on carbon emissions in 1991 which has applied throughout our period of observation. The tax is a general one, and applies to all sectors, but manufacturing industries have from the introduction of the tax been granted a tax credit. The tax credit is unified and identical across industries. But in addition to the general tax credit, the most energy intensive, and thus the most emission intensive industries, defined as those with a CO2 tax bills exceeding 0.8 percent of their production value, get a further tax credit. ${ }^{4}$ Sweden is also part of European Union Emissions Trading System (EU-ETS) which was set up in 2005 to reduce $\mathrm{CO} 2$ emissions. The EU-ETS applies only to firms in the energy intensive sectors. Our period of observation coincide partly with the so called first and second trading periods of EU-ETS (2005-2007 and 2008-2012). Note that quotas were in general distributed for free during these trading periods, and the price of quotas in the second hand market has been very low due to the recession in Europe during the second trading period.

\subsection{Basic Facts on CO2 Emissions and Trade}

The manufacturing sector is responsible for around 40 percent of the $\mathrm{CO} 2$ emissions in Sweden. But needless to say there are huge differences in CO2 intensities across individual industries. The energy intensive industries have much higher emissions as well as emission intensities (CO2 emissions relative to output) than the other industries. So far the interindustry variations have got the most attention from academics and policy makers. Hence, also analyses of $\mathrm{CO} 2$ emissions and international trade have until recently mainly focused on differences in emissions across sectors and industries as surveyed by Copeland and Taylor (2004) and Brunnermeier and Levinson (2004). However, a simple decomposition of the variation in $\mathrm{CO} 2$ emission intensity of Swedish manufacturing firms into (i) variation

\footnotetext{
${ }^{4}$ The energy intensive sectors are paper and pulp (17), coke and refined petroleum products (19), chemicals (20), non-metalic mineral products (23), and basic metals (24).
} 
across firms within sectors and (ii) variation between sectors, shows that the majority of the variation in emission intensity can be ascribed to firm heterogeneity within actually rather narrowly sectors. According to Table 1, almost 70 percent of the variation in $\mathrm{CO} 2$ emissions is due to differences between firms rather than inter-sectoral differences.

Table 1: Decomposistion of CO2 emissions

\begin{tabular}{lcc}
\hline \hline & Within sector (5 digit) & Between sectors \\
$\mathrm{CO} 2$ emission intensity & $67 \%$ & $33 \%$ \\
\hline \hline Note: CO2 emission intensity is measured as CO2 emissions relative to output.
\end{tabular}

Our hypothesis is that the inter-firm differences in emission intensities may be linked to other heterogeneous characteristics of the firms and in particular to their internationalization. Analyses of various countries (see e.g. Bernard et al, 2007) have shown that exporters are bigger, more productive and more capital intensive. As shown in Table 2, our data for Swedish manufacturing confirms these stylized facts.

Table 2: Firm characteristics: Exporters versus Non-Exporters

\begin{tabular}{lcccccc}
\hline \hline & \multicolumn{3}{c}{ Exporters } & \multicolumn{3}{c}{ Non-Exporters } \\
& obs. & mean & std.dev. & obs. & mean & std.dev. \\
Productivity (TFP) & 44966 & 9172 & 18233 & 123139 & 2977 & 4285 \\
Capital/labour (tSEK/employee) & 46904 & 444 & 7921 & 139656 & 310 & 2391 \\
Employees & 46904 & 83.7 & 499 & 139656 & 6.4 & 34 \\
\hline \hline
\end{tabular}

Turning to the relationship between exporting and emission intensity Table 3 report average $\mathrm{CO} 2$ emission intensity for exporters versus non-exporters for all manufacturing sectors as well as for energy intensive and non-energy intensive sectors separately. ${ }^{5}$ The picture is not quite clear. But we note that in the non-energy intensive sectors, which account for more than 80 percent of manufacturing employment exporters' emission intensity is on average lower. Doing a count of industries, we also find that in 17 out of 24 manufacturing industries (2 digit level) exporters' CO2 emission intensity is lower than that of non-exporters.

Table 3: Decomposistion of CO2 emissions

\begin{tabular}{lccc}
\hline \hline CO2 emission intensity & All sectors & Energy intensive sectors & Non-energy intensive sectors \\
Exporters & 9114 & 28081 & 5524 \\
Non-Exporters & 6176 & 15610 & 5855 \\
\hline \hline
\end{tabular}

Note: CO2 emission intensity is measured as CO2 emissions relative to output.

Out of 24 manufacturing industries, there are 5 energy intensive and 19 non-energy intensive.

\footnotetext{
${ }^{5}$ The energy intensive sectors are paper and pulp (17), coke and refined petroleum products (19), chemicals (20), non-metalic mineral products (23), and basic metals (24).
} 
Motivated by the facts on CO2 emissions and their variation across firms, we proceed by developing a simple theory of heterogeneous firms where firms within an industry differ in their emissions. In particular, we propose and develop a mechanism for why emissions may differ across firms, and why export performance may have an impact on firms' emissions. Moreover, we let the theory be guided by the environmental tax regime facing Swedish manufacturing firms.

\section{The Model}

We develop a model with international trade and heterogeneous firms (see Melitz (2003)) whose production entails emitting CO2. Firms that are productive enough to set up production make two distinct decisions, whether to enter the export market and how much to invest in abatement to reduce emissions. Firms make these decision subject to trade costs and emission taxes.

We consider the case of two countries, Home and Foreign (denoted by "*"). Each economy is active in the production in two industries: a monopolistic competitive industry $(M)$ where firms produce differentiated goods under increasing returns and subject to $\mathrm{CO} 2$ emissions, and a background industry $(A)$ characterized by perfect competition and which produces homogenous goods subject to constant returns to scale. To make things simple, we shall assume that there is just one factor of production. This may be a composite factor, but for the sake of simplicity we shall refer to it as labor. We present the equations describing Homels consumers and firms, and note that corresponding equations apply to Foreign.

The theoretical model allows us to derive analytical expressions for equilibrium emission intensity and equilibrium abatement investments, and to analyze the relationship between emission intensity, abatement investment and trade. Our analysis delivers predictions export performance, emission and abatement. In Section 4 we proceed by testing empirically these theoretical predictions using the Swedish manufacturing firm level data.

\subsection{Demand}

Consumers preferences are given by a two-tier utility function with the upper tier (CobbDouglas) determining the representative consumer's division of expenditure between goods produced in sectors $A$ and $M$, and the second tier (CES), giving the consumer's preferences over the continuum of differentiated varieties produced within the manufacturing sector. Hence, all individuals in Home have the utility function

$$
U=C_{M}^{\mu} C_{A}^{1-\mu},
$$


where $\mu \in(0,1)$ and $C_{A}$ is consumption of the homogenous good. Goods produced in the $A$ sector can be costlessly traded internationally and are produced under constant returns to scale and perfect competition. The $A$-good is chosen as the numeraire, so that the world market price of the agricultural good, $p_{A}$, is equal to unity. By choice of scale, the labor requirement in the A-sector is one, which gives

$$
p_{A}=w=1
$$

and thus, wages are normalized to one across both countries and sectors. We assume that demand for $A$ goods is sufficiently large to guarantee that the $A$ sector is active in both countries. The consumption of goods from the $M$ sector is defined as an aggregate $C_{M}$,

$$
C_{M}=\left[\int_{i \in I} c(i)^{(\sigma-1) / \sigma} d i\right]^{\sigma /(\sigma-1)}
$$

where $c(i)$ represents consumption of each variety with elasticity of substitution between any pair of differentiated goods being $\sigma>1$. The measure of the set $I$ represents the mass of varieties consumed in the Home country. Each consumer spends a share $\mu$ of his income on goods from industry $M$, and the demand for each single variety produced locally and in the foreign country is therefore given by respectively

$$
\begin{aligned}
& x_{d}=\frac{p^{-\sigma}}{P^{1-\sigma}} \mu Y \\
& x_{e}=\frac{\tau^{1-\sigma}\left(p^{*}\right)^{-\sigma}}{P^{1-\sigma}} \mu Y,
\end{aligned}
$$

where $p$ is the consumer price, $Y$ is income, and $P \equiv\left(\int_{i \in I} p(i)^{1-\sigma} d i\right)^{\frac{1}{1-\sigma}}$ the price index of $M$ goods consumed in the Home country. Products from Foreign sold in Home incur an iceberg trade cost $\tau$, i.e. for each unit of a good from Foreign to arrive in Home, $\tau>1$ units must be shipped. It is assumed that trade costs are equal in both directions.

\subsection{Entry, Exit and Production Costs in the M Sector}

To enter the $M$ sector in country $j$, a firm bears the fixed costs of entry $f_{E}$ measured in labour units. After having sunk $f_{E}$, an entrant draws a labour-per-unit-output coefficient $a$ from a cumulative distribution $G(a)$. We follow Helpman et al. (2004) in assuming the probability distribution to be a Pareto distribution, ${ }^{6}$ i.e. $G(a)=\left(\frac{a}{a_{0}}\right)^{k}$, where $k$ is the shape parameter, and we normalize the scale parameter to unity, $a_{0} \equiv 1$. Since $a$ is unit labour requirement, 1/a depicts labour productivity. Upon observing this draw, a firm

\footnotetext{
${ }^{6}$ This assumption is consistent with the empirical findings by e.g. Axtell (2001).
} 
may decide to exit and not produce. If it chooses to stay, it bears the additional fixed overhead costs, $f_{D}$. If the firm does not only want to serve the domestic market but also wants to export, it has to bear the additional fixed costs, $f_{X}$. Hence, firm technology is represented by a cost function that exhibits a variable cost and a fixed overhead cost. In the absence of emissions and abatement investment, labour is used as a linear function of output according to

$$
l=f+a x
$$

with $f=f_{D}$ for firms only serving the domestic market and $f=f_{D}+f_{X}$ for exporters. We make the simplifying assumption that not just variable costs but also all types of fixed costs are incurred in labor. However, since we do not focus on issues related to factor markets or comparative advantage, this only serves as means to simplify the analysis, without having any impact on the results.

Industrial activity in sector $M$ entails pollution in terms of emission of CO2. We follow Copeland and Taylor (2003) and assume that each firm produces two outputs: an industrial good $(x)$ and emissions $(e)$. In order to reduce emissions, a firm can divert a fraction $\theta$ of the primary factor, labour, away from the production of $x$. We may think of $\theta$ as a variable abatement expenditure that is chosen optimally by each firm. The joint production of industrial goods and emissions is given by

$$
\begin{gathered}
x=(1-\theta) \frac{l}{a} \\
e=\varphi(\theta) \frac{l}{a}
\end{gathered}
$$

with $0 \leq \theta<1$. Emissions are determined by the abatement function

$$
\varphi(\theta)=\frac{(1-\theta)^{1 / \alpha}}{h\left(f_{A}\right)}
$$

which is characterized by $\varphi(0)=1, \varphi(1)=0, \varphi^{\prime}()<$.0 and $0<\alpha<1$. The abatement function reflects that firms may reduce their emission intensity through two types of abatement activities that incur variable and fixed costs respectively. As already noted, $\theta$ determines the variable abatement costs, while $f_{A}$ represent investments in abatement, e.g. machines and equipment that allow for reduced emissions. ${ }^{7}$ A given reduction of emissions may be reached either through increased $\theta$ or through increased $f_{A}$, since we assume $h^{\prime}\left(f_{A}\right)>0$.

We proceed by using (7) to substitute for in (8), and in turn (8) to substitute for $\theta$ in (6), which gives us an integrated expression for the joint production of goods and

\footnotetext{
${ }^{7}$ We depart from the standard formulation of the abatement function in the literature on trade and emissions by assuming that firms can have an impact on emission intensity through fixed abatement investments $\left(f_{A}\right)$.
} 
emission, and exploits the fact that although pollution is an output, it can equivalently also be treated as an input: ${ }^{8}$

$$
x=\left(h\left(f_{A}\right) e\right)^{\alpha}\left(\frac{l}{a}\right)^{1-\alpha} .
$$

Hence, with such an interpretation, production implies the use of labor as well as emission. Note that while firms are heterogeneous with respect to labour productivity and abatement, they are identical with respects to the structure of their basic production technology and face the same tax rate on emissions. Firms minimize costs subject to the production function $(9)$, taking wages $(w=1)$ and emission taxes $(t>0)$ as given. Disregarding the sunk entry cost $\left(f_{E}\right)$ we can derive firms' total cost function using (5) and (9).

$$
C=f+f_{A}+\kappa\left(\frac{t}{h\left(f_{A}\right)}\right)^{\alpha} a^{(1-\alpha)} x
$$

with $\kappa \equiv \alpha^{-\alpha}(1-\alpha)^{\alpha-1}$ and where $f=f_{D}$ for firms only serving the domestic market, and $f=f_{D}+f_{X}$ for exporters, i.e. firms serving both the domestic and the foreign market. The cost function reflects that emissions are not for free, rather they incur a tax $t>0$. But through increasing their investments in abatement, firms can reduce their emissions as well as their tax bill. Hence, in contrast to the other fixed costs, investment in abatement is an endogenous variable.

Our analysis focuses on steady-state equilibria and intertemporal discounting is ignored. The present value of firms is kept finite by assuming that firms face a constant Poisson hazard rate $\delta$ of 'death' independently of productivity. An entering firm with productivity $a$ will immediately exit if its profit level $\pi(a)$ is negative, or will produce and earn $\pi(a) \geq 0$ in every period until it is hit by a bad shock and forced to exit.

\subsection{Profit Maximization}

Having drawn their productivity, firms follow a two-step decision process. First, they decide on abatement investment, and second, taking abatement as given, they maximize profits. We solve their problem using backwards induction: Firms first calculate their optimal pricing rule given abatement investments, second they make their decision on abatement investment given the optimal pricing rule. Implicitly they then also decide on emission intensity and on share of input factor to divert away from production and towards abatement, i.e. the variable costs of abatement.

Each producer operates under increasing returns to scale at the plant level and in line with Dixit and Stiglitz (1977), we assume there to be large group monopolistic competition between the producers in the $M$ sector. Thus, the perceived elasticity of demand equals

\footnotetext{
${ }^{8}$ See Copeland and Taylor (2003) for a discussion of this feature of the model.
} 
the elasticity of substitution between any pair of differentiated goods and is equal to $\sigma$. Regardless of its productivity, each firm then chooses the same profit maximizing markup over marginal costs $(M C)$ equal to $\sigma /(\sigma-1)$. This yields a pricing rule

$$
p=\frac{\sigma}{\sigma-1} M C
$$

for each producer. Using (4) and (10) we can formulate the expression for firms' profits. We let super- and subscript $D$ and $X$ denote non-exporters and exporters respectively. Firms only serving the domestic market earn profits

$$
\pi_{D}=\left(a^{1-\alpha}\left(\frac{t}{h\left(f_{A}\right)}\right)^{\alpha}\right)^{1-\sigma} B-f_{D}-f_{A}
$$

while the exporting firms, serving both the local and the foreign market, earn profits

$$
\pi_{X}=\left(a^{1-\alpha}\left(\frac{t}{h\left(f_{A}\right)}\right)^{\alpha}\right)^{1-\sigma}\left(B+\phi B^{*}\right)-f_{D}-f_{X}-f_{A},
$$

where $B \equiv \frac{\kappa^{1-\sigma} \sigma^{-\sigma}(\sigma-1)^{\sigma-1} \mu L}{P^{1-\sigma}}$ in an index of the market potential of the home country, and $B^{*} \equiv \frac{\kappa^{1-\sigma} \sigma^{-\sigma}(\sigma-1)^{\sigma-1} \mu L^{*}}{\left(P^{*}\right)^{1-\sigma}}$ depicts the market potential of the foreign country, and $\phi=\tau^{1-\sigma} \in\langle 0,1]$ depicts the freeness of trade.

\subsection{Fixed Cost Investments in Abatement}

Having solved the second stage of firms' decision problem, we proceed to the first stage. In order to be able to derive explicit analytical expression for abatement investments we employ the specific functional form $h\left(f_{A}\right)=f_{A}^{\rho}$, with $\rho>0$. Since firms' profits depend on whether they are exporters or non-exporters, abatement investments will differ between the two groups of firms. Maximizing non-exporting firms' profits with respect to abatement investments $f_{A}$ using (12) gives:

$$
f_{A}^{D}=\Omega B^{\frac{1}{\beta}} t^{-\frac{\alpha(\sigma-1)}{\beta}} a^{-\frac{(1-\alpha)(\sigma-1)}{\beta}}
$$

with $\beta \equiv 1-\alpha \rho(\sigma-1)$ and $\Omega \equiv(\alpha \rho(\sigma-1))^{\frac{1}{\beta}}$, while the optimal investment in abatement for exporters is found using (13):

$$
f_{A}^{X}=\Omega\left(B+\phi B^{*}\right)^{\frac{1}{\beta}} t^{-\frac{\alpha(\sigma-1)}{\beta}} a^{-\frac{(1-\alpha)(\sigma-1)}{\beta}} .
$$

From (14) and (15) follow that firms' abatement investments depend on their exogenously given marginal productivity, taxes, and the market potential. ${ }^{9}$ An internal solution to the

\footnotetext{
${ }^{9}$ Note that the effects of trade liberalisation (a higher $\phi$ ) cannot be seen from this equation since $B$ and $B^{*}$ are functions of $\phi$.
} 
profit maximizing choice of $f_{A}^{D}$ and $f_{A}^{X}$, requires that $\beta>0$. However, as this condition is a necessary condition for profit maximization, we assume it always to hold, see section A.1 in the Appendix for details. Having examined (14) and (15) we can formulate the following propositions on the relationship between abatement investments and firm characteristics.

Proposition 1 More productive firms invest more in abatement.

Proof: The statement follows directly from (14) and (15).

The logic behind this result is that more productive firms have higher sales. Hence, the exploiting of scale economies makes it profitable for them to make a higher investment in order to reduce marginal costs.

Proposition 2 For any given level of productivity, exporters invest more in abatement than non-exporters.

Proof: Since $\left(\frac{B+\phi B^{*}}{B}\right)^{\frac{1}{\beta}}>1$ it follows from (14) and (15) that $f_{A}^{X}>f_{A}^{D}$ for any given productivity level $(1 / a)$.

\subsection{Cut off Conditions and Free Entry}

Finally, based on equilibrium abatement investments, we can now determine the cut off conditions the two types of active firms. The cut off productivity level for firms only serving the domestic market $\left(1 / a_{D}\right)$ identifies the lowest productivity level of producing firms. From (12) and (13), we see that profits are increasing in firms' productivity. The least productive firms expect negative profits and therefore exit the industry. This applies to all firms with a unit labor input coefficient above $a_{D}$, the point at which profits from domestic sales equal zero, and is determined by

$$
\left(a_{D}^{1-\alpha}\left(\frac{t}{h\left(f_{A}^{D}\right)}\right)^{\alpha}\right)^{1-\sigma} B=f_{D}+f_{A}^{D}
$$

With $\sigma>1$ it follows that $a^{(1-\alpha)(1-\sigma)}$ increases along with productivity and can thus be used as a productivity index. Exporters' abatement investments affect the production and profits earned both in the home market and the foreign market. The cut-off productivity level for exporters $\left(a_{X}\right)$ identifies the lowest productivity level of exporting firms, and is given by the productivity level where the export profits plus the net extra profit in the home market from the higher abatement investments equals the extra fixed costs incurred by exporting and the incremental investment in abatement:

$$
\left(a_{X}^{1-\alpha}\left(\frac{t}{h\left(f_{A}^{X}\right)}\right)^{\alpha}\right)^{1-\sigma} \phi B^{*}+\left(a_{X}^{1-\alpha}\left(\frac{t}{h\left(f_{A}^{X}\right)}\right)^{\alpha}\right)^{1-\sigma} B-\left(a_{X}^{1-\alpha}\left(\frac{t}{h\left(f_{A}^{D}\right)}\right)^{\alpha}\right)^{1-\sigma} B=f_{X}+f_{A}^{X}-f_{A}^{D},
$$


We note that since abatement investments have an impact on firms' marginal costs, it also affects the profitability of being a domestic versus an exporting firm. ${ }^{10}$

The model is closed by the free-entry condition

$$
f_{E}=\int_{0}^{a_{X}} \pi_{X} d G(a)+\int_{0}^{a_{D}} \pi_{D} d G(a) .
$$

\subsection{CO2 Emissions}

Taking abatement investment as given, firms decide on their use of labour as well as on emissions. As we are primarily interested in emissions, we shall focus on these. Firms' participation in trade affects their investment in abatement and therefore the emission intensity (emissions relative to output) of firms.

The general expression for emission intensity is found by using Shepard's lemma on the cost function (10) as we exploit that due to the special features of the model, emissions appear not only as an output of production, but also as an input to production:

$$
\frac{e}{x}=\alpha \kappa t^{\alpha-1} f_{A}^{-\rho \alpha} a^{1-\alpha}
$$

We see that there is a simple relationship between abatement investment and emission intensity. The more a firm invest in abatement, the lower its emission intensity. Using (14) and (15), to substitute in (19) gives the emission intensity of non-exporters and exporters respectively:

$$
\begin{gathered}
\frac{e^{D}}{x}=\alpha \kappa t^{\frac{\alpha-\beta}{\beta}} B^{-\frac{\rho \alpha}{\beta}}\left(\frac{1}{1-\beta}\right)^{\frac{\rho \alpha}{\beta}} a^{\frac{1-\alpha}{\beta}} \\
\frac{e^{X}}{x}=\alpha \kappa t^{\frac{\alpha-\beta}{\beta}}\left(B+\phi B^{*}\right)^{-\frac{\rho \alpha}{\beta}}\left(\frac{1}{1-\beta}\right)^{\frac{\rho \alpha}{\beta}} a^{\frac{1-\alpha}{\beta}}
\end{gathered}
$$

A set of results on the relationship between emissions, firm characteristics, taxes and trade emerge directly from equations (20) and (21):

Proposition 3 More productive firms have a lower emission intensity.

Proof: The statement follows directly from equations (20) and (21).

Proposition 4 For any given level of productivity, an exporter would have a lower emission intensity than a non-exporter.

Proof: The statement follows from (20), (21), and the fact that $\left(B+\phi B^{*}\right)^{-\frac{\rho \alpha}{\beta}}<B^{-\frac{\rho \alpha}{\beta}}$.

\footnotetext{
${ }^{10}$ The paper is in this sense related to the literature on trade induced technological upgrading. See e.g. Bas (2008) and Bustos (2011).
} 
Note that the latter proposition is based on a thought experiment, since according to the model, depending on productivity level a firm is either an exporter or a nonexporter. There is no such productivity level at which some firms are exporters and some are non-exporters.

\subsection{Trade Liberalization, Abatement and CO2 Emissions}

Eventually we want to investigate the relationship between trade liberalization, abatement and emissions. In order to analyze the effects of trade liberalization we need to solve the model. This requires that we make additional assumptions with respect to market size. We proceed by assuming that the two economies are identical regarding tax regime and market size. Hence, we solve the model for $t=t^{*}$ and $B=B^{*}$. Due to symmetry it suffices to solve for equilibrium in the home country. Equations (14), (15), (16), (17), and (18) determine the endogenous variables $\bar{f}_{A}^{D}, \bar{f}_{A}^{X}, \bar{a}_{D}, \bar{a}_{X}$, and $\bar{B}$, where we use upper bar to denote equilibrium values derived based on the symmetry assumption. This gives us the following two expressions for the cut-off productivities: ${ }^{11}$

$$
\begin{aligned}
& \bar{a}_{D}^{k}=\left.\frac{f_{E}}{\left(\frac{\gamma}{k \beta-\gamma}\right) f_{D}\left(\left((\phi+1)^{\frac{1}{\beta}}-1\right)^{\frac{k \beta}{\gamma}} f_{D}^{\frac{k \beta}{\gamma}}-1\right.} f_{X}^{1-\frac{k \beta}{\gamma}}+1\right) \\
& \bar{a}_{X}^{k}=\frac{f_{E}}{\left(\frac{\gamma}{k \beta-\gamma}\right) f_{X}\left(1+\left((\phi+1)^{\frac{1}{\beta}}-1\right)^{-\frac{k \beta}{\gamma}} f_{X}^{\frac{k \beta}{\gamma}-1} f_{D}^{1-\frac{k \beta}{\gamma}}\right)},
\end{aligned}
$$

with $0<\beta \equiv 1-\alpha \rho(\sigma-1)<1$, and $\gamma \equiv(1-\alpha)(\sigma-1)>0$. Note that the equilibrium expressions reduce to the standard Melitz (2003) cut-off conditions for $\alpha=0$, in which case production does not entail any emissions. Exporters are more productive than nonexporters, i.e. $a_{X}<a_{D}$, as long as $\frac{f_{X}}{f_{D}\left((1+\phi)^{\frac{1}{\beta}}-1\right)}>1$, and we assume this to hold. ${ }^{12}$ We also assume that $k \beta>\gamma$, which guaranties that the cut off productivities are positive. ${ }^{13}$ From (22) and (23) follow that trade liberalization will make the domestic cut-off tougher, i.e. $\bar{a}_{D}$ decreases, and the export cut-off easier, i.e. $a_{X}$ increases, which is line with the results in the standard Melitz model.

Trade liberalization and abatement investments

Using (16) and substituting for the cut off productivity employing (22) we can calculate $\bar{B}$. Substituting this into $(14)$ and $(15)$ we derive the abatement investments for nonexporters $\left(\bar{f}_{A}^{D}\right)$ and exporters $\left(\bar{f}_{A}^{X}\right)$ for the symmetric equilibrium case:

\footnotetext{
${ }^{11}$ See the Appendix Section A.7 for details on calculation.

${ }^{12}$ The corresponding condition in the standard Melitz model is $\frac{f_{X}}{f_{D} \phi}>1$.

${ }^{13}$ The condition may be written: $\frac{k}{\sigma-1}>1-\alpha+\alpha k \rho$, which reduces to the standard condition that $\frac{k}{\sigma-1}>1$ for $\alpha=0$.
} 


$$
\begin{gathered}
\bar{f}_{A}^{D}=\left(\frac{1-\beta}{\beta}\right) f_{D}\left(\frac{a}{\bar{a}_{D}}\right)^{-\frac{\gamma}{\beta}}, \\
\bar{f}_{A}^{X}=\left(\frac{1-\beta}{\beta}\right)(1+\phi)^{\beta} f_{D}\left(\frac{a}{\bar{a}_{D}}\right)^{-\frac{\gamma}{\beta}},
\end{gathered}
$$

We can now formulate the following proposition on the effect of trade liberalization on abatement investments:

Proposition 5 Trade liberalization (higher $\phi$ ) will decrease non-exporting firms' abatement investments. Trade liberalization will always increase exporters' abatement investments for sufficiently high trade costs.

Proof: See Section A.2 in the Appendix.

Trade liberalization increases competition, and leads to lower sales for the non-exporters. This implies that the least productive firms close down and the remaining firms lower their abatement investments. Exporters also face increased competition in the domestic market, but on the other hand they also experience higher sales in the foreign market as trade is liberalized. For high level of trade costs, the latter effects dominate and leads to increased investments in abatement. However, as trade costs reach a low level, the former effect gets stronger and as a consequence, investments in abatement may be reduced.

Trade liberalization and emission intensity

Next, we turn to the effect of trade liberalization. Again we use (16) and (22) to calculate $\bar{B}$, and substitute this into (20) and (21) in order to derive emission intensities for domestic firms and exporters for the symmetric case:

$$
\begin{gathered}
\frac{\bar{e}^{D}}{\bar{x}}=\alpha \kappa t^{\alpha-1} f_{D}^{-\rho \alpha} \bar{a}_{D}^{-\frac{(1-\beta)}{\beta}(1-\alpha)}\left(\frac{\beta}{1-\beta}\right)^{\rho \alpha} a^{\frac{(1-\alpha)}{\beta}}, \\
\frac{\bar{e}^{X}}{\bar{x}}=\alpha \kappa t^{\alpha-1} f_{D}^{-\rho \alpha}(1+\phi)^{-\frac{\rho \alpha}{\beta}} \bar{a}_{D}^{-\frac{(1-\beta)}{\beta}(1-\alpha)}\left(\frac{\beta}{1-\beta}\right)^{\rho \alpha} a^{\frac{(1-\alpha)}{\beta}} .
\end{gathered}
$$

Making use of (22), gives us the following propositions:

Proposition 6 Trade liberalization (a higher $\phi$ ) leads to a higher emission intensity among non-exporters. Trade liberalization leads to a lower emission intensity among exporters if $k>(\phi+1)^{\frac{1}{\beta}}$.

Proof: See Section A.3 in the Appendix.

We observe that the higher the initial level of trade costs prior to liberalization, the more likely is it that trade liberalization will have a benign impact on emissions.

Trade liberalization and total emissions 
Trade liberalization affects emissions by weeding out some of the least productive firms with low abatement investments and accordingly high emission intensities. For relatively high levels of initial trade costs trade liberalization moreover induces exporters to invest more in abatement, which in turn lowers their emission intensity. However, trade liberalization also implies lower abatement investments by non-exporters and larger production volumes as such for the exporters, both of which contribute to higher total emissions. The overall effect of trade liberalization depends on the net effect of this set of effects. We proceed by analyzing total emissions by the non-exporters and the exporters separately. Total emissions are finally given by the sum of these. Total emissions by non-exporters and exporters are given by the integrals

$$
\bar{E}_{D}=\bar{n} \int_{\bar{a}_{X}}^{\bar{a}_{D}} \bar{e} d G\left(a \mid \bar{a}_{D}\right)
$$

and

$$
\bar{E}_{X}=\bar{n} \int_{0}^{\bar{a}_{X}} \bar{e} d G\left(a \mid \bar{a}_{D}\right)
$$

Solving these integrals conditional on firm entry gives the expressions for emissions of non-exporters and exporters respectively. The derivation of these expressions is found in the Appendix Section A.7. Total emissions of non-exporters are given by

$$
\bar{E}_{D}=\frac{\alpha(\sigma-1)\left(1-\left(\left((\phi+1)^{\frac{1}{\beta}}-1\right) \frac{f_{D}}{f_{X}}\right)^{\frac{k \beta}{\gamma}-1}\right)}{\sigma\left(1+\phi(1+\phi)^{\frac{1-\beta}{\beta}}\left(\left((\phi+1)^{\frac{1}{\beta}}-1\right) \frac{f_{D}}{f_{X}}\right)^{\frac{k \beta}{\gamma}-1}\right)} t^{-1} \mu L .
$$

The expression leads to the following proposition:

Proposition 7 Trade liberalization decreases total emissions of non-exporting firms.

Proof: The proposition follows directly from (30), given our assumption that $k \beta>\gamma$. The weeding out of the least productive and dirtiest firms together with lower production volumes for those remaining lead to falling emissions by non-exporters. Trade liberalization also leads to a lower mass of firms, which also contributes lower emissions. These benign effects on emissions overshadow the fact that all non-exporters decrease their abatement emissions (see Proposition 5).

Total emissions by exporters are given by

$$
\bar{E}_{X}=\frac{\alpha(\sigma-1)}{\sigma\left(\left(\frac{f_{X}}{f_{D}}\right)^{\frac{k \beta}{\gamma}-1}(1+\phi)^{-\frac{1}{\beta}}\left((1+\phi)^{\frac{1}{\beta}}-1\right)^{1-\frac{k \beta}{\gamma}}+\frac{\phi}{(1+\phi)}\right)} t^{-1} \mu L .
$$


Even if the condition in Proposition 6 holds, so that the emission intensity of exporters decrease, this group of firms always increases its emissions because of increased total production volume:

Proposition 8 Trade liberalization increases total emissions from exporters.

Proof: See section A.4 in the Appendix.

The question now is what the overall effect of on emissions is. Adding emissions by exporters and non-exporters give

$$
\bar{E}=\frac{\alpha(\sigma-1)}{\sigma}\left(\frac{1-\left(\frac{f_{X}}{f_{D}}\right)^{1-\frac{k \beta}{\gamma}}(1+\phi)^{\frac{1}{\beta}}\left((1+\phi)^{\frac{1}{\beta}}-1\right)^{\frac{k \beta}{\gamma}}}{\left(1+\left(\frac{f_{X}}{f_{D}}\right)^{1-\frac{k \beta}{\gamma}} \phi(1+\phi)^{\frac{1}{\beta}-1}\left((1+\phi)^{\frac{1}{\beta}}-1\right)^{\frac{k \beta}{\gamma}-1}\right)}\right) t^{-1} \mu L
$$

which leads to the following proposition:

Proposition 9 Trade liberalization, i.e. higher $\phi$, decreases total emissions.

Proof: The proposition follows directly from (32).

Hence, we find that in the case with symmetric countries, the overall effect of trade liberalization is to decrease emissions. Trade increases production volumes but the combined effect of the weeding out of low productive and dirty firms, the higher abatement investments by exporters, and the shift of production from dirty non-exporters to relatively clean exporters, leads to lower overall emissions. Note that emissions implied by transportation are accounted for in the analysis due to how they are modelled. Iceberg transportation costs imply that transportation costs are in incurred terms of the good transported, and emissions related to the production of the quantity that is absorbed by transportation are thus accounted for in equation (32).

\section{Empirical Design and Results}

Our theoretical model suggests that exporters have relatively lower emission intensity than non-exporters. We have proposed a mechanism through which firms' export status affects their abatement investment and ultimately their emission intensity, which may explain the relationship between emission intensity and export status. We proceed by taking the model's predictions of the relationship on firms' productivity, exporting and emission intensity, as well as on productivity, exporting and abatement investments to the data. The theoretical model suggests log linear specifications for both relationships (see equations (14), (15), (20) and (21)). Hence, we proceed by regressing the firm's emission intensity and abatement respectively on productivity and exporting status, 


$$
\begin{aligned}
\ln \text { Emission intensity }_{i t} & =\alpha_{0}+f\left(\log \text { productivity }_{i t}\right)+\alpha_{2} \text { Exporter }_{i t}+\varepsilon_{i} \\
\ln \text { Abatement investment }_{i t} & =\alpha_{0}+f\left(\log \text { productivity }_{i t}\right)+\alpha_{2} \text { Exporter }_{i t}+\varepsilon_{i}
\end{aligned}
$$

where $f$ is a polynomial function of firm $i^{\prime} s$ productivity in year $t$ and Exporter $_{i t}$ equals one if the firm exports in year $t$, and zero otherwise. ${ }^{14}$ According to our theory productivity is the forcing variable. It drives the export status of a firm as well as the firm level emission intensity (CO2 emissions/Output). However, while productivity has a continuos effect on the emission intensity, the model predicts a discontinuous jump down in the emission intensity when we compare an exporter to a non-exporter. We exploit this by including firm productivity in a very flexible manner using a continuos polynomial up to the fourth order as reflected by $f()$.

\subsection{CO2 Emission Intensity and Exports}

We start by estimating equation (33). Emission intensity is measured as firm-level CO2 emissions per output. Firms' productivity is measured by total factor productivity, and is calculated from estimates of productivity functions using the method by Levinsohn and Petrin (2003). ${ }^{15}$ To account for sectorial variations in emissions we include industry dummies based on 5-digit industries, while year dummies pick up trends as well as the slight changes over time in the emission tax facing Swedish firms. We report regression results where errors are clustered at the firm level, while noting that clustering at the sector level gives very similar results.

In Table 4 we report the OLS results for estimations based on the entire sample. We report results for five different specifications with respect to the modelling of the productivity variable. In line with what our theory would predict, we find that the coefficients for the exporter dummy are negative and significant at the one percent level in all specifications. Exporters emit on average around 12 percent less per unit of output than non-exporters active in the same industry. ${ }^{16}$ There are obviously huge variations in emission intensity across industries. Hence, including industry dummies increases the Rsquare substantially. We have also explored the impact of using industry dummies based on a more aggregate industry classification (2 digit level). Not surprisingly, the results are roughly the same as with the finer classification, but the fit of the model as suggested by the R-square is reduced. As for year dummies, we have also run the regressions without them, but the exclusion of these dummies does not affect the results in any significant way.

\footnotetext{
${ }^{14}$ Export status is defined by exporting income $>0$.

${ }^{15}$ Production functions are estimated at the two-digit sector level, where we use value added as measure of firm output. Explanatory variables are labour (measured by the wage bill) and capital. Finally we use raw materials as proxy for contemporaneous productivity shocks. All variables are in logs.

${ }^{16}$ Which is found using that $100 *(\exp (-0.13)-1)=12$.
} 
Table 4: CO2 emission intensity, productivity and exporting (OLS), I

\begin{tabular}{lccccc}
\hline \hline & & \multicolumn{4}{c}{ Dependent variable: $\ln$ CO2 emission intensity } \\
& $(1)$ & $(2)$ & $(3)$ & $(4)$ & $(5)$ \\
\hline Exporter & $-.323^{a}$ & $-.128^{a}$ & $-.131^{a}$ & $-.133^{a}$ & $-.133^{a}$ \\
& $(.036)$ & $(.037)$ & $(.037)$ & $(.037)$ & $(.037)$ \\
ln TFP & none & linear & 2nd order & 3rd order & 4 th order \\
& & & polynom. & polynom. & polynom. \\
Industry dummies & Yes & Yes & Yes & Yes & Yes \\
Year dummies & Yes & Yes & Yes & Yes & Yes \\
R-squared & .31 & .34 & .34 & .34 & .34 \\
No. of obs. & 30469 & 29965 & 29965 & 29965 & 29965 \\
\hline
\end{tabular}

Note: OLS estimates are based on the panel 2004-2011. Errors are clustered at the firm level.

$\mathrm{CO} 2$ emission intensity gives the ratio of emissions to output. Industry dummies are based on 5 digit industries.

${ }^{a}$ significant at $1 \%$ level, ${ }^{b}$ significant at $5 \%$ level, ${ }^{c}$ significant at $10 \%$ level.

Since emission tax rates, in general, do not vary between firms we control for the slight changes in the emission tax over time by including time fixed effects. However, the most energy intensive industries enjoy a tax credit for the part of their CO2 tax bill which exceeds 0.8 percent of their production value. The same group of firms has since 2005 gradually become included in the EU Emission Trading System. Both these features may have an impact on firms' behavior and thus on their CO2 emissions.

Hence, to allow for variation between the energy and non-energy intensive industries, we proceed by splitting the sample into energy intensive industries and non energy intensive industries. The results are reported for both groups of industries in Table 5. The general message from above is confirmed: exporting firms has a lower emission intensity. Comparing the results for the two groups of firms, the coefficient for export status for the energy intensive firms is much larger but not as strongly significant as in the regressions for low energy intensive sectors. The energy intensive group contains many of the large exporters in the heavy processing industry (paper, pulp, steel etc.) which are also the most substantial emitters of $\mathrm{CO} 2 .{ }^{17}$ As for the results for the non-energy intensive industries these are very similar to those for the complete sample.

\footnotetext{
${ }^{17}$ The energyintensive sectors are Paper and pulp (17), Coke and refined petrolium prod. (19), Chemicals (20), Non-metalic mineral products (23), and Basic metals (24):
} 
Table 5: CO2 emission intensity, productivity and exporting (OLS), II

\begin{tabular}{lcccc|cccc}
\hline \hline & \multicolumn{8}{c}{ Dependent variable: ln CO2 emission intensity } \\
& \multicolumn{7}{c}{ Energy intensive industries } & \multicolumn{5}{c}{ Non-energy intensive industries } \\
& $(1)$ & $(2)$ & $(3)$ & $(4)$ & $(5)$ & $(6)$ & $(7)$ & $(8)$ \\
\hline Exporter & $-.290^{b}$ & $-.317^{b}$ & $-.256^{c}$ & $-.283^{c}$ & $-.095^{a}$ & $-.100^{a}$ & $-.101^{a}$ & $-.094^{a}$ \\
& $(.146)$ & $(.144)$ & $(.145)$ & $(.146)$ & $(.037)$ & $(.037)$ & $(.037)$ & $(.037)$ \\
ln TFP & linear & 2nd order & 3rd order & 4th order & linear & 2nd order & 3rd order & 4 th order \\
& & polynom. & polynom. & polynom. & & polynom. & polynom. & polynom. \\
Industry dummies & Yes & Yes & Yes & Yes & Yes & Yes & Yes & Yes \\
Year dummies & Yes & Yes & Yes & Yes & Yes & Yes & Yes & Yes \\
R-squared & .39 & .42 & .42 & .42 & .31 & .31 & .31 & .31 \\
No. obs. & 3693 & 3693 & 3693 & 3693 & 26272 & 26272 & 26272 & 26272 \\
\hline \hline
\end{tabular}

Note: Estimates are based on the panel 2004-2011. Errors are clustered at the firm level.

$\mathrm{CO} 2$ emission intensity gives the ratio of emissions to output. Industry dummies are based on 5 digit industries.

${ }^{a}$ significant at $1 \%$ level, ${ }^{b}$ significant at $5 \%$ level, ${ }^{c}$ significant at $10 \%$ level.

One may, however, argue that calculating emission intensity based on output may gives inaccurate measures of the firms' emission intensity. Our choice of value of production output as denominator is guided by our theory, but if firms outsource substantial shares of their production, using value added would provide more correct measures of the firms' emission intensity. Reviewing the data, this is nevertheless not an obvious choice since a number of firms run deficits and appear with negative value added. We also observe that the value added fluctuates much more over the years than output does. Hence, our baseline regression are all based on emission intensity calculated using output. Still, in section A.5 in the Appendix we report results both for the entire sample as well as for the energy and non-energy intensive industries using value added rather than value of output to calculate emission intensity. The results are in line with those based on output. Exporting firms do in general have a lower emission intensity. This is also true for the non-energy intensive firms, while the results for the energy intensive firms are weaker.

\subsection{Abatement and Exports}

Next, we turn to the relationship between exporting, productivity and firm level abatement being the proposed theoretical mechanism for why export status affects firms' CO2 emission intensity. The model again suggests a log-linear specification and we estimate a model based on (34). ${ }^{18}$ Abatement data are based on a more limited survey than the emission intensity data. The survey is described in section 2.1 and is biased towards larger firms. This leaves us with a more limited sample than what was the case when we analyzed emission. Hence, identification of the impact of exporting as such is more

\footnotetext{
${ }^{18}$ Yearly firm level abatement investments vary between 0 and more than 400 mio SEK. In order not to exclude the firms with zero abatement investments from the sample as we use logs, we let the dependent variable be $\ln ($ abatement investments +1$)$.
} 
challenging. In Table 6 we report the results from estimating equation (34) using OLS. Again, we report results for five different specifications with respect to the modelling of the productivity variable. We include time and industry (5 digit level) dummies in all regressions. Our results suggest that exporters make significantly higher investment in abatement than non-exporters. Controlling for industry, an exporter invests on average 65 percent more in abatement than a non-exporter. ${ }^{19}$

Table 6: Abatement, productivity and exporting (OLS), I

\begin{tabular}{lccccc}
\hline \hline & \multicolumn{5}{c}{ Dependent variable: ln Abatement Investments } \\
& $(1)$ & $(2)$ & $(3)$ & $(4)$ & $(5)$ \\
\hline Exporter & $1.070^{a}$ & $.505^{b}$ & $.528^{a}$ & $.482^{b}$ & $.494^{b}$ \\
& $(.215)$ & $(.203)$ & $(.203)$ & $(.202)$ & $(.203)$ \\
ln TFP & none & linear & 2nd order & 3rd order & 4 th order \\
& & & polynom. & polynom. & polynom. \\
Industry dummies & Yes & Yes & Yes & Yes & Yes \\
Year dummies & Yes & Yes & Yes & Yes & Yes \\
R-squared & .30 & .36 & .36 & .36 & .36 \\
No. obs. & 7733 & 7575 & 7575 & 7575 & 7575 \\
\hline
\end{tabular}

Note: OLS estimates are based on the panel 2000-2011. Errors are clustered at the firm level. Industry dummies are based on 5 digit industries.

${ }^{a}$ significant at $1 \%$ level, ${ }^{b}$ significant at $5 \%$ level, ${ }^{c}$ significant at $10 \%$ level.

As noted above, we also need to take into consideration the fact that firms in the energy intensive industries faces a threshold for their tax bill and have since 2005 gradually become included in the EU Emission Trading System. Both these features may have an impact on firms' behavior and thus on their CO2 emissions. Hence, we proceed as we did when analyzing emission intensities by splitting the sample into energy and non-energy intensive industries. Results are reported in Table 7 . When it comes to the energy intensive industries, we note that 98 percent of these firms are exporters. This enhances the identification problem further, and not surprisingly exporter status does not have any significant impact on abatement investments. But as we turn to the non-energy intensive industries, we find that, in line with what our theory would predict, exporting firms make higher investments in abatement.

\footnotetext{
${ }^{19}$ Which is found using that $100 *(\exp (0.5)-1)=65$.
} 
Table 7: Abatement, productivity and exporting (OLS), II

\begin{tabular}{lcccc|cccc}
\hline & \multicolumn{8}{c}{ Dependent variable: ln } \\
& \multicolumn{5}{c}{ Ebatement Investments } \\
& $(1)$ & $(2)$ & $(3)$ & $(4)$ & $(5)$ & $(6)$ & $(7)$ & $(8)$ \\
\hline Exporter & -.288 & -.294 & -.227 & -.356 & $.612^{a}$ & $.653^{a}$ & $.623^{a}$ & $.606^{a}$ \\
& $(.724)$ & $(.724)$ & $(.747)$ & $(.746)$ & $(.200)$ & $(.203)$ & $(.201)$ & $(.200)$ \\
ln TFP & linear & 2nd order & 3rd order & 4 th order & linear & 2nd order & 3rd order & 4 th order \\
& & polynom. & polynom. & polynom. & & polynom. & polynom. polynom. \\
Industry dummies & Yes & Yes & Yes & Yes & Yes & Yes & Yes & Yes \\
Year dummies & Yes & Yes & Yes & Yes & Yes & Yes & Yes & Yes \\
R-squared & .46 & .47 & .47 & .47 & .27 & .27 & .27 & .27 \\
No. obs. & 1801 & 1801 & 1801 & 1801 & 5774 & 5774 & 5774 & 5774 \\
\hline \hline
\end{tabular}

Note: Estimates are based on the panel 2000-2011. Errors are clustered at the firm level.

Industry dummies are based on 5 digit industries.

${ }^{a}$ significant at $1 \%$ level, ${ }^{b}$ significant at $5 \%$ level, ${ }^{c}$ significant at $10 \%$ level.

\subsection{Robustness}

One concern is that we estimate the productivity polynomial for a range of the productivity distribution that lacks common support. We therefore reestimate (33) dropping all observations outside the region of common support for exporters and non-exporters within each 5-digit sector. The results with CO2-emission intensity as dependent variable are shown in Table 8. Reassuringly results are almost identical to the estimates with the full sample in spite of dropping about 13 percent of the sample.

Table 8: CO2 emission intensity; OLS on common support

\begin{tabular}{lccccc}
\hline \hline & & \multicolumn{4}{c}{ Dependent variable: $\ln$ CO2 emission intensity } \\
& $(1)$ & $(2)$ & $(3)$ & $(4)$ & $(5)$ \\
\hline Exporter & $-.278^{a}$ & $-.133^{a}$ & $-.131^{a}$ & $-.122^{a}$ & $-.120^{a}$ \\
& $(.036)$ & $(.036)$ & $(.036)$ & $(.036)$ & $(.036)$ \\
ln TFP & none & linear & 2nd order & 3rd order & 4 th order \\
& & & polynom. & polynom. & polynom. \\
Industry dummies & Yes & Yes & Yes & Yes & Yes \\
Year dummies & Yes & Yes & Yes & Yes & Yes \\
R-squared & .31 & .30 & .30 & .30 & .30 \\
No. obs. & 26007 & 26007 & 26007 & 26007 & 26007 \\
\hline \hline
\end{tabular}

Note: OLS estimates are based on the panel 2004-2011. Errors are clustered at the firm level.

Observations outside the common support in each 5-digit sector are dropped.

$\mathrm{CO} 2$ emission intensity gives the ratio of emissions to output. Industry dummies are based on 5 digit industries.

${ }^{a}$ significant at $1 \%$ level, ${ }^{b}$ significant at $5 \%$ level, ${ }^{c}$ significant at $10 \%$ level.

We also reestimate equation (34) with abatement as dependent variable on a sample with common support for exporters and non-exporters. Estimating with common support 
implies in this case dropping 36 percent of the sample. As shown in Table 9, the results are nevertheless very similar to the regressions results based on the full sample.

Table 9: Abatement; OLS on common support

\begin{tabular}{lccccc}
\hline \hline & \multicolumn{5}{c}{ Dependent variable: ln Abatement investments } \\
& $(1)$ & $(2)$ & $(3)$ & $(4)$ & $(5)$ \\
\hline Exporter & $0.793^{a}$ & $.479^{b}$ & $.492^{b}$ & $.461^{b}$ & $.465^{b}$ \\
& $(.200)$ & $(.195)$ & $(.195)$ & $(.196)$ & $(.195)$ \\
ln TFP & none & linear & 2nd order & 3rd order & 4 th order \\
& & & polynom. & polynom. & polynom. \\
Industry dummies & Yes & Yes & Yes & Yes & Yes \\
Year dummies & Yes & Yes & Yes & Yes & Yes \\
R-squared & .25 & .28 & .28 & .29 & .29 \\
No. obs. & 4833 & 4833 & 4833 & 4833 & 4833 \\
\hline \hline
\end{tabular}

Note: OLS estimates are based on the panel 2000-2011. Errors are clustered at the firm level.

Observations outside the common support in each 5-digit sector are dropped.

Industry dummies are based on 5-digit industries.

${ }^{a}$ significant at $1 \%$ level, ${ }^{b}$ significant at $5 \%$ level, ${ }^{c}$ significant at $10 \%$ level.

\section{Conclusion}

This paper analyses CO2 emissions and exporters within a framework with heterogeneous firms and trade. We develop a theoretical model that proposes a mechanism for why exporters may be expected to have lower emission intensities than non-exporters: In line with the standard theory on heterogeneous firms and trade, the most productive firms become exporters. Exporters' larger production scale supports higher fixed investments in abatement which in turn reduces both their emission tax bills and their emission intensity. Hence, according to our model we would expect emission intensity to be negatively related to firm-level productivity and export status.

Solving the model for symmetric countries we find that trade liberalization allows for a higher production volume and make new exporters cleaner as they are induced to invest more in abatement. But trade liberalization also makes non-exporters dirtier as these firms are forced to downsize and reduce their investments in abatement. We show that the overall effect of trade liberalization is to reduce emissions. This is a result of the less productive and dirtiest firms being weeded out, and of production being shifted from relatively dirty non-exporters to more efficient and cleaner exporting firms.

A unique data set for Swedish manufacturing firms that includes information on firmlevel abatement investments and firm-level emissions of CO2 allows us to test the empirical predictions of the model on the relationship between productivity, export status and emission intensity as well as on productivity, export status and abatement investments. Productivity is the forcing variable in our model. It drives the firm level emission intensity 
(CO2 emissions/Output) as well as the export status of a firm. While productivity has a continuos effect on the emission intensity, the model predicts a discontinuous jump down in the emission intensity as we compare exporters to non-exporters. We therefore estimate the relationships between exporting, abatement and emission intensity controlling for firm productivity in a very flexible manner using a continuos polynomial up to the fourth order. The empirical results strongly support the notion that the firm-level CO2 emission intensity is negatively related to firm productivity and to being an exporter. The estimated coefficient for the entire sample implies that exporters have on average a 12 percent lower emission intensity.

Investigating the relationship between abatement investments and export status is more challenging. The abatement data is collected based on a survey biased towards lager firms, which leaves us with both a smaller and less representative sample than what was the case when we analyzed emission intensity. But the estimated coefficients are in line with what the theory predicts, and suggest that there is a positive relationship between exporting and productivity on the hand side and abatement on the other side. The empirical results suggest that exporters invest on average 65 percent more in abatement.

The paper provides both theoretical arguments as well as empirical evidence of one mechanism whereby which international trade can have a benign effect working against climate change, as it promotes investments abatement, leads to lower CO2 emission intensity and lower total emissions. We also provide evidence on exporters having lower emission intensity. These effects of trade on CO2 emissions stand in stark contrast to the predictions of e.g. the pollution haven hypothesis, which suggests that international trade will tend to increase emissions, as it decreases the effects of environmental regulations by making it easier for firms to expand polluting activities in countries with less stringent environmental standards. 


\section{References}

[1] Antweiler, W., B. R. Copeland and M. S. Taylor (2001), "Is Free Trade Good for the Environment?" American Economic Review 91 (4), pp. 877-908.

[2] Axtell, R. L. (2001), "Zipf distribution of U.S. firm sizes", Science 293.

[3] Bas M. (2012), "Technology Adoption, Export Status and Skill Upgrading: Theory and Evidence", Review of International Economics 20(2), 315-331

[4] Batrakova, S. and R. B. Davies, (2012). "Is there an environmental benefit to being an exporter? Evidence from firm level data", Review of World Economics 148(3), pp. 449-474.

[5] Bernard, A., J. Bradford Jensen, S. Redding and Peter Schott (2007), "Firms in International Trade", Journal of Economic Perspectives, 21(3), pp.105-130.

[6] Brunnermeier, S. and A. Levinson (2004), "Examining the evidence on environmental regulations and industry location", Journal of Environment and Development 13, pp.6-41.

[7] Bustos, P. (2011). "Trade Liberalization, Exports, and Technology Upgrading: Evidence on the Impact of MERCOSUR on Argentinian Firms", American Economic Review 101(1), pp. 304-340.

[8] Copeland, B.R. and M.S. Taylor (1995), "Trade and Transboundary Pollution", American Economic Review (85), pp. 716-737.

[9] Copeland, B.R. and M.S. Taylor (2003), Trade and the Environment. Theory and Evidence. Princeton University Press, 2003.

[10] Copeland, B.R. and M.S. Taylor (2004), "Trade, Growth, and the Environment", Journal of Economic Literature 42(1), pp. 7-71.

[11] Dixit, A. K. and J. E. Stiglitz (1977) "Monopolistic Competition and Optimum Product Diversity", American Economic Review 67(3), 297-308

[12] Ederington, J., A. Levinson and J. Minier, (2004). "Trade Liberalization and Pollution Havens," The B.E. Journal of Economic Analysis \& Policy, Berkeley Electronic Press 4(2), 6 .

[13] Frankel, J. A. and Rose, A. K. (2005), "Is Trade Good or Bad for the Environment? Sorting Out the Causality", The Review of Economics and Statistics 87(1), pp.85-91.

[14] Helpman, E., M. J. Melitz, and S. R. Yeaple, (2004). "Export versus FDI with Heterogeneous Firms",American Economic Review 94(1), pp. 300-316. 
[15] Holladay, S. "Are Exporters Mother Nature's Best Friends?", mimeo, 2011.

[16] Levinsohn, J. and A. Petrin. (2003). "Estimating production functions using inputs to control for unobservables", Review of Economic Studies 70(2), pp. 317-342.

[17] Levinson, A and M. S. Taylor, (2008). "Unmasking The Pollution Haven Effect," International Economic Review 49(1), pp. 223-254.

[18] Levinson, A. (2009). "Technology, International Trade, and Pollution from US Manufacturing," American Economic Review 99(5), pp. 2177-92.

[19] Levinson, A. (2010), "Offshoring Pollution: Is the US Increasingly Importing Pollution Intensive Production?" Review of Environmental Economics and Policy 4(1), pp. 63-83.

[20] Melitz, M.J. (2003), "The Impact of Trade on Intra-Industry Reallocations and Aggregate Industry Productivity", Econometrica 71(6), pp 1695-1725.

[21] Rodriguea, J. and O. Soumonnia (2014) "Deforestation, Foreign Demand and Export Dynamics in Indonesia", forthcoming, Journal of International Economics 


\section{A Appendix}

\section{A.1 Optimal abatement and productivity level}

The optimal level of abatement investments is given by:

$$
f_{A}^{D}=\left\{\frac{1}{B}\left(a^{1-\alpha} t^{\alpha}\right)^{\sigma-1} \frac{1}{\alpha \rho(\sigma-1)}\right\}^{\frac{1}{\alpha \rho(\sigma-1)-1}}=\Omega_{D} a^{\frac{(1-\alpha)(\sigma-1)}{\alpha \rho(\sigma-1)-1}}
$$

We differentiate optimal abatement level with respect to productivity level:

$$
\frac{\partial f_{A}^{D}}{\partial a}=\frac{(1-\alpha)(\sigma-1)}{\alpha \rho(\sigma-1)-1} \Omega_{D} a^{\frac{(1-\alpha)(\sigma-1)}{\alpha \rho(\sigma-1)-1}-1}<0
$$

i.e. abatement investments are increasing in firms' productivity level, provided that:

$$
\alpha \rho(\sigma-1)-1<0
$$

However, we assume this condition will always hold, as it is a necessary condition for profit maxmization:

$$
\frac{\partial^{2} \pi_{D}}{\partial\left(f_{A}^{D}\right)^{2}}=(\alpha \rho(\sigma-1)-1) \alpha \rho(\sigma-1)\left(a^{1-\alpha} t^{\alpha}\right)^{1-\sigma}\left(f_{A}^{D}\right)^{-\alpha \rho(1-\sigma)-2} B<0 \quad \nabla \quad \alpha \rho(\sigma-1)-1<0
$$

and it implies that abatement has a decreasing marginal effect on firms' profit:

\section{A.2 Proof of Proposition 5}

A.2.1 Proof that $\frac{d \bar{f}_{A}^{D}}{d \phi}<0$

The cut-off of non-exporters is given by:

$$
\bar{a}_{D}=\left(\frac{f_{E}}{\left(\frac{\gamma}{k \beta-\gamma}\right) f_{D}\left(\left((\phi+1)^{\frac{1}{\beta}}-1\right)^{\frac{k \beta}{\gamma}} f_{D}^{\frac{k \beta}{\gamma}-1} f_{X}^{1-\frac{k \beta}{\gamma}}+1\right)}\right)^{\frac{1}{k}}
$$

From this equation follows that:

$$
\frac{d \bar{a}_{D}}{d \phi}<0
$$

Next, the abatement investments by non-exporters are given by:

$$
\bar{f}_{A}^{D}=\left(\frac{1-\beta}{\beta}\right) f_{D}\left(\frac{a}{\bar{a}_{D}}\right)^{-\frac{\gamma}{\beta}}
$$


From this equation follows that:

$$
\frac{d \bar{f}_{A}^{D}}{d \bar{a}_{D}}>0
$$

Thus, using (40) and (42), we have that:

$$
\frac{d \bar{f}_{A}^{D}}{d \phi}=\frac{d \bar{f}_{A}^{D}}{d \bar{a}_{D}} \frac{d \bar{a}_{D}}{d \phi}<0
$$

\section{A.2.2 Proof of condition for $\frac{d \bar{f}_{A}^{X}}{d \phi}>0$}

The abatement investment by exporters is given by:

$$
\bar{f}_{A}^{X}=\left(\frac{1-\beta}{\beta}\right)(1+\phi)^{\beta} f_{D}\left(\frac{a}{\bar{a}_{D}}\right)^{-\frac{\gamma}{\beta}}
$$

Differentiating w.r.t. $\phi$ gives:

$$
\begin{aligned}
\frac{\partial \bar{f}_{A}^{X}}{\partial \phi} & =\frac{\partial \bar{f}_{A}^{X}}{\partial \phi}+\frac{\partial \bar{f}_{A}^{X}}{\partial \bar{a}_{D}} \frac{d \bar{a}_{D}}{d \phi} \\
& =\bar{f}_{A}^{X} \frac{\beta}{1+\phi}+\bar{f}_{A}^{X} \frac{\gamma}{\beta \bar{a}_{D}} \frac{d \bar{a}_{D}}{d \phi} \\
& =\bar{f}_{A}^{X}\left(\frac{\beta}{1+\phi}+\frac{\gamma}{\beta \bar{a}_{D}} \frac{d \bar{a}_{D}}{d \phi}\right)
\end{aligned}
$$

The term $\frac{d \bar{a}_{D}}{d \phi}$ is from $(22)$ :

$$
\frac{d \bar{a}_{D}}{d \phi}=-\frac{\bar{a}_{D}\left((\phi+1)^{\frac{1}{\beta}}-1\right)^{\frac{k \beta}{\gamma}-1}(\phi+1)^{\frac{1}{\beta}-1}}{\gamma\left(\left((\phi+1)^{\frac{1}{\beta}}-1\right)^{\frac{k \beta}{\gamma}}+f_{D}^{1-\frac{k \beta}{\gamma}} f_{X}^{\frac{k \beta}{\gamma}-1}\right)}
$$

Substituting into (44) gives:

$$
\frac{\partial \bar{f}_{A}^{X}}{\partial \phi}=\bar{f}_{A}^{X}\left(\frac{\beta}{1+\phi}-\frac{\left((\phi+1)^{\frac{1}{\beta}}-1\right)^{\frac{k \beta}{\gamma}-1}(\phi+1)^{\frac{1}{\beta}-1}}{k \beta\left(\left((\phi+1)^{\frac{1}{\beta}}-1\right)^{\frac{k \beta}{\gamma}}+f_{D}^{1-\frac{k \beta}{\gamma}} f_{X}^{\frac{k \beta}{\gamma}-1}\right)}\right)
$$

Hence, $\frac{\partial \bar{f}_{A}^{X}}{\partial \phi}>0$ iff

$$
\frac{\beta}{1+\phi}>\frac{\left((\phi+1)^{\frac{1}{\beta}}-1\right)^{\frac{k \beta}{\gamma}-1}(\phi+1)^{\frac{1}{\beta}-1}}{\beta\left(\left((\phi+1)^{\frac{1}{\beta}}-1\right)^{\frac{k \beta}{\gamma}}+f_{D}^{1-\frac{k \beta}{\gamma}} f_{X}^{\frac{k \beta}{\gamma}-1}\right)}
$$


which can be rewritten as:

$$
\beta^{2}\left(\left((\phi+1)^{\frac{1}{\beta}}-1\right)^{\frac{k \beta}{\gamma}}+\left(\frac{f_{X}}{f_{D}}\right)^{\frac{k \beta}{\gamma}-1}\right)>(\phi+1)^{\frac{1}{\beta}}\left((\phi+1)^{\frac{1}{\beta}}-1\right)^{\frac{k \beta}{\gamma}-1}
$$

By inspection, the inequality holds for $\phi$ close enough to autarky $(\phi=0)$. For free trade $(\phi=1)$ the condition may or may not hold depending on parameter values.

\section{A.3 Proof of Proposition 6}

First, the emission intensity of non-exporters is given by:

$$
\frac{\bar{e}^{D}}{\bar{x}}=\alpha \kappa t^{\alpha-1} f_{D}^{-\rho \alpha} \bar{a}_{D}^{-\frac{(1-\beta)}{\beta}(1-\alpha)}\left(\frac{\beta}{1-\beta}\right)^{\rho \alpha} a^{\frac{(1-\alpha)}{\beta}}
$$

Differentiation w.r.t. $\phi$ gives

$$
\frac{d \frac{\bar{e}^{D}}{\bar{x}}}{d \phi}=\frac{d \frac{\bar{e}^{D}}{\bar{x}}}{d \bar{a}_{D}} \frac{d \bar{a}_{D}}{d \phi}>0
$$

since $\alpha, \beta<1$ and $\frac{d \bar{a}_{D}}{d \phi}<0$ from (45).

Next, the emission intensity of exporters is given by:

$$
\frac{\bar{e}^{X}}{\bar{x}}=\alpha \kappa t^{\alpha-1} f_{D}^{-\rho \alpha}(1+\phi)^{-\frac{\rho \alpha}{\beta}} \bar{a}_{D}^{-\frac{(1-\beta)}{\beta}(1-\alpha)}\left(\frac{\beta}{1-\beta}\right)^{\rho \alpha} a^{\frac{(1-\alpha)}{\beta}}
$$

Differentiation w.r.t. $\phi$ gives:

$$
\begin{aligned}
\frac{d \frac{\bar{e}^{X}}{\bar{x}}}{d \phi} & =\frac{d \frac{\bar{e}^{X}}{\bar{x}}}{d \phi}+\frac{d \frac{\bar{e}^{X}}{\bar{x}}}{d \bar{a}_{D}} \frac{d \bar{a}_{D}}{d \phi} \\
& =-\frac{\bar{e}^{X}}{\bar{x}} \frac{1}{\beta}\left(\frac{\rho \alpha}{1+\phi}+\frac{(1-\beta)(1-\alpha)}{\bar{a}_{D}} \frac{d \bar{a}_{D}}{d \phi}\right) \\
& =-\frac{\bar{e}^{X}}{\bar{x}} \frac{1}{\beta}\left(\frac{\rho \alpha}{1+\phi}-\frac{(1-\beta)(1-\alpha)\left((\phi+1)^{\frac{1}{\beta}}-1\right)^{\frac{k \beta}{\gamma}-1}(\phi+1)^{\frac{1}{\beta}-1}}{k \gamma\left(\left((\phi+1)^{\frac{1}{\beta}}-1\right)^{\frac{k \beta}{\gamma}}+f_{D}^{1-\frac{k \beta}{\gamma}} f_{X}^{\frac{k \beta}{\gamma}-1}\right)}\right)
\end{aligned}
$$

The differential is negative as long as the expression inside the parenthesis is negative:

$$
\rho \alpha>\frac{(1-\beta)(1-\alpha)\left((\phi+1)^{\frac{1}{\beta}}-1\right)^{\frac{k \beta}{\gamma}-1}(\phi+1)^{\frac{1}{\beta}}}{k \gamma\left(\left((\phi+1)^{\frac{1}{\beta}}-1\right)^{\frac{k \beta}{\gamma}}+f_{D}^{1-\frac{k \beta}{\gamma}} f_{X}^{\frac{k \beta}{\gamma}-1}\right)}
$$

Now using that $\beta \equiv 1-\alpha \rho(\sigma-1)<1$, and $\gamma \equiv(1-\alpha)(\sigma-1)>0$, this allows us to 
simplify the expression

$$
k>\frac{\left((\phi+1)^{\frac{1}{\beta}}-1\right)^{\frac{k \beta}{\gamma}-1}(\phi+1)^{\frac{1}{\beta}}}{\left(\left((\phi+1)^{\frac{1}{\beta}}-1\right)^{\frac{k \beta}{\gamma}}+f_{D}^{1-\frac{k \beta}{\gamma}} f_{X}^{\frac{k \beta}{\gamma}-1}\right)}
$$

which can be rewritten according to

$$
k>\frac{\left((\phi+1)^{\frac{1}{\beta}}-1\right)^{-1}(\phi+1)^{\frac{1}{\beta}}}{\left(1+\frac{f_{D}^{1-\frac{k \beta}{\gamma}} f_{X}^{\frac{k \beta}{\gamma}}-1}{\left((\phi+1)^{\frac{1}{\beta}}-1\right)^{\frac{k \beta}{\gamma}}}\right)}=\frac{\frac{1}{\left(1-\frac{1}{(\phi+1)^{\frac{1}{\beta}}}\right)}}{\left(1+\frac{f_{D}^{1-\frac{k \beta}{\gamma}} f_{X}^{\frac{k \beta}{\gamma}}-1}{\left((\phi+1)^{\frac{1}{\beta}}-1\right)^{\frac{k \beta}{\gamma}}}\right)}=\frac{(\phi+1)^{\frac{1}{\beta}} \frac{f_{X}}{f_{D}\left((\phi+1)^{\frac{1}{\beta}}-1\right)}}{\frac{f_{X}}{f_{D}}+\left(\frac{f_{X}}{f_{D}\left((\phi+1)^{\frac{1}{\beta}}-1\right)}\right)^{\frac{k \beta}{\gamma}}}
$$

Note now that we have assumed that $\frac{f_{X}}{f_{D}\left((1+\phi)^{\frac{1}{\beta}}-1\right)}>1$, and that $\frac{k \beta}{\gamma}>1$. We can therefore write the condition as:

$$
\frac{k}{(\phi+1)^{\frac{1}{\beta}}}>1>\frac{\frac{f_{X}}{f_{D}\left((\phi+1)^{\frac{1}{\beta}}-1\right)}}{\frac{f_{X}}{f_{D}}+\left(\frac{f_{X}}{f_{D}\left((\phi+1)^{\frac{1}{\beta}}-1\right)}\right)^{\frac{k \beta}{\gamma}}}
$$

This implies that $k>(\phi+1)^{\frac{1}{\beta}}$ is a sufficient condition for $\frac{d \frac{\bar{e}^{X}}{\bar{x}}}{d \phi}<0$.

\section{A.4 Proposition 9}

$$
\begin{aligned}
\bar{E}_{X} & =\frac{\alpha(\sigma-1)}{\sigma\left(\left(\frac{f_{X}}{f_{D}}\right)^{\frac{k \beta}{\gamma}-1}(1+\phi)^{-\frac{1}{\beta}}\left((1+\phi)^{\frac{1}{\beta}}-1\right)^{1-\frac{k \beta}{\gamma}}+\frac{\phi}{(1+\phi)}\right)} t^{-1} \mu L \\
& =\alpha\left(\frac{\sigma-1}{\sigma}\right) t^{-1} \mu L\left(\left(\frac{f_{X}}{f_{D}}\right)^{\frac{k \beta}{\gamma}-1}(1+\phi)^{-\frac{1}{\beta}}\left((1+\phi)^{\frac{1}{\beta}}-1\right)^{1-\frac{k \beta}{\gamma}}+\frac{\phi}{(1+\phi)}\right)^{-1} \\
& =\Psi\left(\Theta(1+\phi)^{-\frac{1}{\beta}}\left((1+\phi)^{\frac{1}{\beta}}-1\right)^{1-\frac{k \beta}{\gamma}}+\frac{\phi}{(1+\phi)}\right)^{-1}
\end{aligned}
$$

where $\Psi=\alpha\left(\frac{\sigma-1}{\sigma}\right) t^{-1} \mu L$ and $\Theta=\left(\frac{f_{X}}{f_{D}}\right)^{\frac{k \beta}{\gamma}-1}$ are parameters. Differentiation w.r.t. $\phi$ gives:

$$
\frac{d \bar{E}_{X}}{d \phi}=-\Psi\left(\Theta(1+\phi)^{-\frac{1}{\beta}}\left((1+\phi)^{\frac{1}{\beta}}-1\right)^{1-\frac{k \beta}{\gamma}}+\frac{\phi}{(1+\phi)}\right)^{-2} K
$$


where

$$
\begin{gathered}
\Theta \equiv \quad-\frac{1}{\beta}(1+\phi)^{-\frac{1}{\beta}-1}\left((1+\phi)^{\frac{1}{\beta}}-1\right)^{1-\frac{k \beta}{\gamma}} \\
\left.+(1+\phi)^{-\frac{1}{\beta}}\left(1-\frac{k \beta}{\gamma}\right)\left(\frac{1}{\beta}(1+\phi)^{\frac{1}{\beta}-1}\right)\left((1+\phi)^{\frac{1}{\beta}}-1\right)^{-\frac{k \beta}{\gamma}}\right\}+\frac{1}{(1+\phi)^{2}}
\end{gathered}
$$

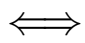

$$
\begin{aligned}
K & \equiv \Theta \frac{1}{\beta}\left\{-(1+\phi)^{-\frac{1}{\beta}-1}\left((1+\phi)^{\frac{1}{\beta}}-1\right)^{1-\frac{k \beta}{\gamma}}-\left(\frac{k \beta}{\gamma}-1\right)(1+\phi)^{-1}\left((1+\phi)^{\frac{1}{\beta}}-1\right)^{-\frac{k \beta}{\gamma}}\right\}+\frac{1}{(1+\phi)^{2}} \\
& \Longleftrightarrow \\
K & \equiv(1+\phi)^{-1}\left(\Theta \frac{1}{\beta}\left\{-(1+\phi)^{-\frac{1}{\beta}}\left((1+\phi)^{\frac{1}{\beta}}-1\right)^{1-\frac{k \beta}{\gamma}}-\left(\frac{k \beta}{\gamma}-1\right)\left((1+\phi)^{\frac{1}{\beta}}-1\right)^{-\frac{k \beta}{\gamma}}\right\}+\frac{1}{(1+\phi)}\right) \\
& \Longleftrightarrow \\
K & \equiv(1+\phi)^{-1}\left(\frac{1}{(1+\phi)}-\Theta \frac{1}{\beta}\left\{(1+\phi)^{-\frac{1}{\beta}}\left((1+\phi)^{\frac{1}{\beta}}-1\right)^{1-\frac{k \beta}{\gamma}}+\left(\frac{k \beta}{\gamma}-1\right)\left((1+\phi)^{\frac{1}{\beta}}-1\right)^{-\frac{k \beta}{\gamma}}\right\}\right)
\end{aligned}
$$

From $(53) \frac{d \bar{E}_{X}}{d \phi}>0$ when $K<0$, that is, when

$$
\frac{1}{(1+\phi)}-\Theta \frac{1}{\beta}\left\{(1+\phi)^{-\frac{1}{\beta}}\left((1+\phi)^{\frac{1}{\beta}}-1\right)^{1-\frac{k \beta}{\gamma}}+\left(\frac{k \beta}{\gamma}-1\right)\left((1+\phi)^{\frac{1}{\beta}}-1\right)^{-\frac{k \beta}{\gamma}}\right\}<0
$$

Substituting in $\Theta=\left(\frac{f_{X}}{f_{D}}\right)^{\frac{k \beta}{\gamma}-1}$ and rearranging (55) implies that $\frac{d \bar{E}_{X}}{d \phi}>0$ when

$$
\begin{aligned}
& \left(\frac{f_{X}}{f_{D}}\right)^{\frac{k \beta}{\gamma}-1} \frac{(1+\phi)}{\beta}\left\{(1+\phi)^{-\frac{1}{\beta}}\left((1+\phi)^{\frac{1}{\beta}}-1\right)^{1-\frac{k \beta}{\gamma}}+\left(\frac{k \beta}{\gamma}-1\right)\left((1+\phi)^{\frac{1}{\beta}}-1\right)^{-\frac{k \beta}{\gamma}}\right\}>1 \\
& \Longleftrightarrow \\
& \left\{\frac{(1+\phi)^{1-\frac{1}{\beta}}}{\beta}\left(\frac{f_{X}}{f_{D}} \frac{1}{(1+\phi)^{\frac{1}{\beta}}-1}\right)^{\frac{k \beta}{\gamma}-1}+\left(\frac{k}{\gamma}-\frac{1}{\beta}\right)\left(\frac{f_{X}}{f_{D}}\right)^{-1}(1+\phi)\left(\frac{f_{X}}{f_{D}} \frac{1}{(1+\phi)^{\frac{1}{\beta}}-1}\right)^{\frac{k \beta}{\gamma}}\right\}>1 \\
& \Longleftrightarrow\left(\frac{f_{X}}{f_{D}} \frac{1}{(1+\phi)^{\frac{1}{\beta}}-1}\right)^{\frac{k \beta}{\gamma}-1}\left\{\frac{(1+\phi)^{1-\frac{1}{\beta}}}{\beta}+\left(\frac{k}{\gamma}-\frac{1}{\beta}\right)\left(\frac{(1+\phi)}{(1+\phi)^{\frac{1}{\beta}}-1}\right)\right\}>1
\end{aligned}
$$

We have assumed that $\frac{f_{X}}{f_{D}\left((1+\phi)^{\frac{1}{\beta}}-1\right)}>1$, which implies that exporters are more productive than non-exporters, and the first term in (56) is therefore larger than one. Moreover, the last term in the parenthesis $\left(\frac{(1+\phi)}{(1+\phi)^{\frac{1}{\beta}}-1}\right)>\left(\frac{(1+\phi)}{(1+\phi)-1}\right)=\frac{1+\phi}{\phi}=1+\frac{1}{\phi}>1$ since 
$\beta<1$, and $\left(\frac{k}{\gamma}-\frac{1}{\beta}\right)>0$ since we have assumed that $\frac{k \beta}{\gamma}>1$. A sufficient condition for $\frac{d \bar{E}_{X}}{d \phi}>0$ is therefore that

$$
\left\{\frac{(1+\phi)^{1-\frac{1}{\beta}}}{\beta}+\left(\frac{k}{\gamma}-\frac{1}{\beta}\right)\right\}>1
$$

Rewriting gives

$$
\left\{(1+\phi)^{1-\frac{1}{\beta}}+\frac{k \beta}{\gamma}\right\}>1+\beta
$$

which always holds since $0<\beta<1$. 


\section{A.5 CO2 emission intensity based on value added}

Table 10: CO2 emission intensity, productivity and exporting (OLS)

\begin{tabular}{lccccc}
\hline \hline & & \multicolumn{4}{c}{ Dependent variable: ln CO2 emission intensity } \\
& $(1)$ & $(2)$ & $(3)$ & $(4)$ & $(5)$ \\
\hline Export dummy & $-.298^{a}$ & $-.121^{a}$ & $-.123^{a}$ & $-.125^{a}$ & $-.127^{a}$ \\
& $(.037)$ & $(.037)$ & $(.037)$ & $(.037)$ & $(.037)$ \\
ln TFP & none & linear & 2nd order & 3rd order & 4 th order \\
(forcing variable) & & & polynom. & polynom. & polynom. \\
Industry dummies & Yes & Yes & Yes & Yes & Yes \\
Year dummies & Yes & Yes & Yes & Yes & Yes \\
R-squared & .31 & .33 & .33 & .33 & .33 \\
No. obs. & 30284 & 29782 & 29782 & 29782 & 29782 \\
\hline \hline
\end{tabular}

Note: OLS estimates are based on the panel 2004-2011. Errors are clustered at the firm level.

$\mathrm{CO} 2$ emission intensity gives the ratio of emissions to value added. Industry dummies are based on 5 digit industries.

${ }^{a}$ significant at $1 \%$ level, ${ }^{b}$ significant at $5 \%$ level, ${ }^{c}$ significant at $10 \%$ level.

Table 11: CO2 emission intensity, productivity and exporting (OLS): Energy and nonenergy intensive industries

\begin{tabular}{lcccc|cccc}
\hline \hline & \multicolumn{9}{c}{ Dependent variable: ln CO2 emission intensity } \\
& \multicolumn{3}{c}{ Energy intensive industries } & \multicolumn{3}{c}{ Non-energy intensive industries } \\
& $(1)$ & $(2)$ & $(3)$ & $(4)$ & $(5)$ & $(6)$ & $(7)$ & $(8)$ \\
\hline Export dummy & -.273 & $-.297^{b}$ & -.241 & -.269 & $-.089^{b}$ & $-.094^{b}$ & $-.095^{b}$ & $-.089^{b}$ \\
& $(.149)$ & $(.147)$ & $(.148)$ & $(.149)$ & $(.038)$ & $(.038)$ & $(.038)$ & $(.038)$ \\
ln TFP & linear & 2nd order & 3rd order & 4th order & linear & 2nd order & 3rd order & 4 th order \\
(forcing variable) & & polynom. & polynom. & polynom. & & polynom. & polynom. & polynom. \\
Industry dummies & Yes & Yes & Yes & Yes & Yes & Yes & Yes & Yes \\
Year dummies & Yes & Yes & Yes & Yes & Yes & Yes & Yes & Yes \\
R-squared & .41 & .41 & .41 & .41 & .30 & .30 & .30 & .30 \\
No. obs. & 3678 & 3678 & 3678 & 3678 & 26104 & 26104 & 26104 & 26104 \\
\hline \hline
\end{tabular}

Note: Estimates are based on the panel 2004-2011. Errors are clustered at the firm level.

CO2 emission intensity gives the ratio of emissions to value added. Industry dummies are based on 5 digit industries.

${ }^{a}$ significant at $1 \%$ level, ${ }^{b}$ significant at $5 \%$ level, ${ }^{c}$ significant at $10 \%$ level. 


\section{A.6 Sector classification}

SNI 2007 Manufacturing industry

$10 \quad$ Manufacture of food products

11 Manufacture of beverages

$12 \quad$ Manufacture of tobacco products

$13 \quad$ Manufacture of textiles

$14 \quad$ Manufacture of wearing apparel

$15 \quad$ Manufacture of leather and related products

16 Manufacture of wood and of products of wood and cork, except furniture; manufacture of articles of straw

$17 \quad$ Manufacture of paper and paper products

$18 \quad$ Printing and reproduction of recorded media

19 Manufacture of coke and refined petroleum products

20 Manufacture of chemicals and chemical products

21 Manufacture of basic pharmaceutical products and pharmaceutical preparations

$22 \quad$ Manufacture of rubber and plastic products

$23 \quad$ Manufacture of other non-metallic mineral products

$24 \quad$ Manufacture of basic metals

$25 \quad$ Manufacture of fabricated metal products, except machinery and equipment

$26 \quad$ Manufacture of computer, electronic and optical products

$27 \quad$ Manufacture of electrical equipment

28 Manufacture of machinery and equipment n.e.c.

$29 \quad$ Manufacture of motor vehicles, trailers and semi-trailers

$30 \quad$ Manufacture of other transport equipment

$31 \quad$ Manufacture of furniture

$32 \quad$ Other manufacturing

33 Repair and installation of machinery and equipment 


\section{A.7 Solving for Symmetric countries}

Assume symmetric taxes and labor supply $(L)$ so that $B=B^{*}$.

\section{A.7.1 Cut-off productivities}

Optimal abatement investments are derived in Section 3.4 in the main text:

$$
\begin{gathered}
f_{A}^{D}=\left\{\frac{1}{B}\left(a^{1-\alpha} t^{\alpha}\right)^{\sigma-1} \frac{1}{1-\beta}\right\}^{-\frac{1}{\beta}} \\
f_{A}^{x}=\left\{\frac{1}{(B+\phi B)}\left(a^{1-\alpha} t^{\alpha}\right)^{\sigma-1} \frac{1}{1-\beta}\right\}^{-\frac{1}{\beta}}
\end{gathered}
$$

where $B \equiv \frac{\kappa^{1-\sigma} \sigma^{-\sigma}(\sigma-1)^{\sigma-1} \mu L}{P^{1-\sigma}}$ is exogenous to the firm. Now calculate relative abatement investments:

$$
\frac{f_{A}^{x}}{f_{A}^{D}}=\left\{\frac{1}{(1+\phi)}\right\}^{-\frac{1}{\beta}}
$$

The Cut-off conditions are found in the main text text in Section 3.5 and are given by:

$$
\begin{gathered}
\left(a_{D}^{1-\alpha}\left(\frac{t}{\left(f_{A}^{D}\right)^{\rho}}\right)^{\alpha}\right)^{1-\sigma} B=f_{D}+f_{A}^{D} \\
\left(a_{X}^{1-\alpha}\left(\frac{t}{\left(f_{A}^{X}\right)^{\rho}}\right)^{\alpha}\right)^{1-\sigma} \phi B+\left(a_{X}^{1-\alpha}\left(\frac{t}{\left(f_{A}^{X}\right)^{\rho}}\right)^{\alpha}\right)^{1-\sigma} B-\left(a_{X}^{1-\alpha}\left(\frac{t}{\left(f_{A}^{D}\right)^{\rho}}\right)^{\alpha}\right)^{1-\sigma} B=f_{X}+f_{A}^{X}-f_{A}^{D}
\end{gathered}
$$

Substituting (59) into (62) gives.

$$
\left(a_{D}^{1-\alpha}\left(\frac{t}{\left\{\frac{1}{B}\left(a_{D}^{1-\alpha} t^{\alpha}\right)^{\sigma-1} \frac{1}{1-\beta}\right\}^{-\frac{\rho}{\beta}}}\right)^{\alpha}\right)^{1-\sigma} B=f_{D}+\left\{\frac{1}{B}\left(a_{D}^{1-\alpha} t^{\alpha}\right)^{\sigma-1} \frac{1}{1-\beta}\right\}^{-\frac{1}{\beta}}
$$

Simplifying and rewriting (64) gives us an expression for $B$ as a function of $a_{D}$ and $t$ :

$$
B=\frac{f_{D}^{\beta} a_{D}^{(1-\alpha)(\sigma-1)} t^{\alpha(\sigma-1)}}{\left(\left(\frac{1}{1-\beta}\right)^{\frac{\rho}{\beta} \alpha(1-\sigma)}-\left\{\frac{1}{1-\beta}\right\}^{-\frac{1}{\beta}}\right)^{\beta}}=\frac{f_{D}^{\beta} a_{D}^{(1-\alpha)(\sigma-1)} t^{\alpha(\sigma-1)}}{\varkappa^{\beta}}
$$

where $\varkappa \equiv\left(\frac{1}{1-\beta}\right)^{\frac{\rho}{\beta} \alpha(1-\sigma)}-\left\{\frac{1}{1-\beta}\right\}^{-\frac{1}{\beta}}=(1-\beta)^{\frac{1-\beta}{\beta}}-\{1-\beta\}^{\frac{1}{\beta}}>0$.

Next we substitute (59) and (60) into (63) to get 


$$
\begin{aligned}
& \left(a_{X}^{1-\alpha}\left(\frac{t}{\left\{\frac{1}{B(1+\phi)}\left(a_{X}^{1-\alpha} t^{\alpha}\right)^{\sigma-1} \frac{1}{1-\beta}\right\}^{-\frac{\rho}{\beta}}}\right)^{\alpha}\right)^{1-\sigma} B(\phi+1) \\
& -\left(a_{X}^{1-\alpha}\left(\frac{t}{\left\{\frac{1}{B}\left(a_{X}^{1-\alpha} t^{\alpha}\right)^{\sigma-1} \frac{1}{1-\beta}\right\}^{-\frac{\rho}{\beta}}}\right)^{\alpha}\right)^{1-\sigma} B \\
& =f_{X}+\left\{\frac{1}{B(1+\phi)}\left(a_{X}^{1-\alpha} t^{\alpha}\right)^{\sigma-1} \frac{1}{1-\beta}\right\}^{-\frac{1}{\beta}}-\left\{\frac{1}{B}\left(a_{X}^{1-\alpha} t^{\alpha}\right)^{\sigma-1} \frac{1}{1-\beta}\right\}^{-\frac{1}{\beta}},
\end{aligned}
$$

which we can simplify and rewrite so as to get $B$ as function of $a_{x}$ and $t$ :

$$
B=\frac{a_{X}^{(1-\alpha)(\sigma-1)} t^{\alpha(\sigma-1)} f_{X}^{\beta}}{\left((1+\phi)^{\frac{1}{\beta}}-1\right)^{\beta} \varkappa^{\beta}}
$$

Using (65) and (67) gives the relative cut-off condition ratio:

$$
\frac{a_{X}^{(1-\alpha)(\sigma-1)}}{a_{D}^{(1-\alpha)(\sigma-1)}}=\left((\phi+1)^{\frac{1}{\beta}}-1\right)^{\beta} \frac{f_{D}^{\beta}}{f_{X}^{\beta}}
$$

Next solve the free entry condition

$$
\begin{aligned}
f_{E} & =\int_{0}^{a_{X}}\left(\left(a^{1-\alpha}\left(\frac{t}{\left(f_{A}^{X}\right)^{\rho}}\right)^{\alpha}\right)^{1-\sigma} B(1+\phi)-f_{D}-f_{X}-f_{A}^{X}\right) d G(a) \\
& +\int_{a_{X}}^{a_{D}}\left[\left(a^{1-\alpha}\left(\frac{t}{\left(f_{A}^{D}\right)^{\rho}}\right)^{\alpha}\right)^{1-\sigma} B-f_{D}-f_{A}^{D}\right] d G(a)
\end{aligned}
$$

Using (14) and (15) to substitute, we get

$$
\begin{aligned}
& f_{E}+a_{X}^{k}\left(f_{D}+f_{X}\right)+\left(a_{D}^{k}-a_{X}^{k}\right) f_{D} \\
& =B^{\frac{1}{\beta}}(1+\phi)^{\frac{1}{\beta}} t^{-\frac{\alpha(\sigma-1)}{\beta}} \varkappa k \int_{0}^{a_{X}} a^{-\frac{(1-\alpha)(\sigma-1)}{\beta}} a^{k-1} d a+B^{\frac{1}{\beta}} t^{-\frac{\alpha(\sigma-1)}{\beta}} \varkappa k \int_{a X}^{a_{D}} a^{-\frac{(1-\alpha)(\sigma-1)}{\beta}} a^{k-1} d a
\end{aligned}
$$

Solving the integral we get 


$$
\begin{aligned}
& f_{E}+a_{X}^{k}\left(f_{D}+f_{X}\right)+\left(a_{D}^{k}-a_{X}^{k}\right) f_{D} \\
& =B^{\frac{1}{\beta}}(1+\phi)^{\frac{1}{\beta}} t^{-\frac{\alpha(\sigma-1)}{\beta}} \varkappa \frac{k \beta}{k \beta-(1-\alpha)(\sigma-1)} a_{X}^{k-\frac{(1-\alpha)(\sigma-1)}{\beta}} \\
& +B^{\frac{1}{\beta}} t^{-\frac{\alpha(\sigma-1)}{\beta}} \varkappa \frac{k \beta}{k \beta-(1-\alpha)(\sigma-1)}\left(a_{D}^{k-\frac{(1-\alpha)(\sigma-1)}{\beta}}-a_{X}^{k-\frac{(1-\alpha)(\sigma-1)}{\beta}}\right)
\end{aligned}
$$

and substituting in the solutions for $B,(65)$ and (67):

$$
\begin{aligned}
& f_{E}+a_{X}^{k}\left(f_{D}+f_{X}\right)+\left(a_{D}^{k}-a_{X}^{k}\right) f_{D} \\
& =\left(\frac{a_{X}^{(1-\alpha)(\sigma-1)} t^{\alpha(\sigma-1)} f_{X}^{\beta}}{\left((1+\phi)^{\frac{1}{\beta}}-1\right)^{\beta} \varkappa^{\beta}}\right)^{\frac{1}{\beta}}(1+\phi)^{\frac{1}{\beta}} t^{-\frac{\alpha(\sigma-1)}{\beta}} \varkappa \frac{k \beta}{k \beta-(1-\alpha)(\sigma-1)} a_{X}^{k-\frac{(1-\alpha)(\sigma-1)}{\beta}} \\
& +\left(\frac{f_{D}^{\beta} a_{D}^{(1-\alpha)(\sigma-1)} t^{\alpha(\sigma-1)}}{\varkappa^{\beta}}\right)^{\frac{1}{\beta}} t^{-\frac{\alpha(\sigma-1)}{\beta}} \varkappa \frac{k \beta}{k \beta-(1-\alpha)(\sigma-1)} a_{D}^{k-\frac{(1-\alpha)(\sigma-1)}{\beta}} a_{X}^{k-\frac{(1-\alpha)(\sigma-1)}{\beta}} \\
& -\left(\frac{a_{X}^{(1-\alpha)(\sigma-1)} t^{\alpha(\sigma-1)} f_{X}^{\beta}}{\left((1+\phi)^{\frac{1}{\beta}}-1\right)^{\beta} \varkappa^{\beta}}\right)^{\frac{1}{\beta}} t^{-\frac{\alpha(\sigma-1)}{\beta}} \varkappa \frac{k \beta}{k \beta-(1-\alpha)(\sigma-1)}
\end{aligned}
$$

gives

$$
f_{E}+a_{X}^{k} f_{X}\left(-\frac{(1-\alpha)(\sigma-1)}{k \beta-(1-\alpha)(\sigma-1)}\right)+a_{D}^{k} f_{D}\left(-\frac{(1-\alpha)(\sigma-1)}{k \beta-(1-\alpha)(\sigma-1)}\right)=0
$$

Now subsitute out $a_{X}$ using (68) to get

$$
\begin{gathered}
f_{E}+a_{D}^{k}\left((\phi+1)^{\frac{1}{\beta}}-1\right)^{\frac{k \beta}{(1-\alpha)(\sigma-1)}} \frac{f_{D}^{\frac{k \beta}{(1-\alpha)(\sigma-1)}}}{f_{X}^{\frac{k \beta}{(1-\alpha)(\sigma-1)}}} f_{X}\left(\frac{-(1-\alpha)(\sigma-1)}{k \beta-(1-\alpha)(\sigma-1)}\right) \\
+a_{D}^{k} f_{D}\left(\frac{-(1-\alpha)(\sigma-1)}{k \beta-(1-\alpha)(\sigma-1)}\right)=0 .
\end{gathered}
$$

and rewrite to get an expression for $a_{D}^{k}$, which gives the equilibrium cut-off productivity for domestic producers

$$
\bar{a}_{D}^{k}=\frac{f_{E}}{\left(\frac{(1-\alpha)(\sigma-1)}{k \beta-(1-\alpha)(\sigma-1)}\right) f_{D}\left(\left((\phi+1)^{\frac{1}{\beta}}-1\right)^{\frac{k \beta}{(1-\alpha)(\sigma-1)}} f_{D}^{\frac{k \beta}{(1-\alpha)(\sigma-1)}-1} f_{X}^{1-\frac{k \beta}{(1-\alpha)(\sigma-1)}}+1\right)}
$$


Using (68) gives the corresponding euilibrium cut-off productivity for exporters in the symmetric case:

$$
\bar{a}_{X}^{k}=\frac{f_{E}}{\left(\frac{(1-\alpha)(\sigma-1)}{k \beta-(1-\alpha)(\sigma-1)}\right) f_{X}\left(1+\frac{1}{\left((\phi+1)^{\frac{1}{\beta}}-1\right)^{\frac{k \beta}{(1-\alpha)(\sigma-1)}} f_{X}^{1-\frac{k \beta}{(1-\alpha)(\sigma-1)} f_{D}^{(1-\alpha)(\sigma-1)}-1}}\right)}
$$

\section{A.7.2 Calculate the price index $(P)$}

We now calculate the price index for the symmetric case. We have that $B \equiv \frac{\kappa^{1-\sigma_{\sigma^{-\sigma}}(\sigma-1)^{\sigma-1} \mu L_{j}}}{P_{j}^{1-\sigma}}=$ $\frac{\varsigma \mu L_{j}}{P_{j}^{1-\sigma}}$, where $\varsigma \equiv \kappa^{1-\sigma} \sigma^{-\sigma}(\sigma-1)^{\sigma-1}$. According to (65) we have that

$$
B=\frac{f_{D}^{\beta} a_{D}^{(1-\alpha)(\sigma-1)} t^{\alpha(\sigma-1)}}{\varkappa^{\beta}}=\frac{\varsigma \mu L_{j}}{P_{j}^{1-\sigma}}
$$

wich can be rewritten as

$$
P=\frac{\varsigma \mu L_{j} \varkappa^{\beta}}{f_{D}^{\beta} a_{D}^{(1-\alpha)(\sigma-1)} t^{\alpha(\sigma-1)}}=\left(\frac{\varkappa}{f_{D}^{-}}\right)^{\frac{\beta}{1-\sigma}}(\varsigma \mu)^{\frac{1}{1-\sigma}} L_{j}^{\frac{1}{1-\sigma}} a_{D}^{(1-\alpha)} t^{\alpha},
$$

and subsituting in for $a_{D}^{k}$ using (73) gives the price index

$$
\begin{aligned}
\bar{P} & =\left(\frac{\varkappa}{f_{D}^{-}}\right)^{\frac{\beta}{1-\sigma}}(\varsigma \mu)^{\frac{1}{1-\sigma}} L_{j}^{\frac{1}{1-\sigma}} t^{\alpha} . \\
& \left(\frac{f_{E}}{\left(\frac{(1-\alpha)(\sigma-1)}{k \beta-(1-\alpha)(\sigma-1)}\right) f_{D}\left(\left((\phi+1)^{\frac{1}{\beta}}-1\right)^{\frac{k \beta}{(1-\alpha)(\sigma-1)}} f_{D}^{\frac{k \beta}{(1-\alpha)(\sigma-1)}-1} f_{X}^{1-\frac{k \beta}{(1-\alpha)(\sigma-1)}}+1\right)}\right)
\end{aligned}
$$

\section{A.7.3 Calculating number of firms in the symmetric case $\left(n=n^{*}\right)$}

The price of an individual variety of a non-exporter is given by (from the main text):

$$
p=\frac{\sigma}{\sigma-1} \kappa\left(\frac{t}{f_{A}^{\rho}}\right)^{\alpha} a^{(1-\alpha)}=\frac{\sigma}{\sigma-1} \kappa t^{\alpha}\left(\bar{f}_{A}^{D}\right)^{\rho \alpha} a^{(1-\alpha)}
$$

After substituting in $\bar{f}_{A}^{D}$ from (14) we get the non-export price

$p=\frac{\sigma}{\sigma-1} \kappa B^{-\frac{\rho \alpha}{\beta}}\left\{\frac{1}{1-\beta}\right\}^{\frac{\rho \alpha}{\beta}} t^{\frac{(1-\beta) \alpha}{\beta}+\alpha} a^{(1-\alpha)+\frac{(1-\alpha)(1-\beta)}{\beta}}=\frac{\sigma}{\sigma-1} \kappa B^{-\frac{\rho \alpha}{\beta}}\left\{\frac{1}{1-\beta}\right\}^{\frac{\rho \alpha}{\beta}} t^{\frac{\alpha}{\beta}} a^{\frac{(1-\alpha)}{\beta}}$

The price of exporters is derived in the same fashion 


$$
\begin{aligned}
p^{*} & =\frac{\sigma}{\sigma-1} \kappa(B+\phi B)^{-\frac{\rho \alpha}{\beta}}\left\{\frac{1}{1-\beta}\right\}^{\frac{\rho \alpha}{\beta}} t^{\frac{(1-\beta) \alpha}{\beta}+\alpha} a^{(1-\alpha)+\frac{(1-\alpha)(1-\beta)}{\beta}} \\
& =\frac{\sigma}{\sigma-1} \kappa(B+\phi B)^{-\frac{\rho \alpha}{\beta}}\left\{\frac{1}{1-\beta}\right\}^{\frac{\rho \alpha}{\beta}} t^{\frac{\alpha}{\beta}} a^{\frac{(1-\alpha)}{\beta}}
\end{aligned}
$$

Next the price index is given by

$$
P=\left(n \int_{o}^{a_{D}} p^{1-\sigma} d G+\phi n \int_{o}^{a_{X}} p^{* 1-\sigma} d G\right)^{\frac{1}{1-\sigma}}
$$

and substituting in for prices in the domestic and foreign market, we get

$$
\begin{aligned}
P=n^{\frac{1}{1-\sigma}} & \frac{\sigma}{\sigma-1} \kappa B^{-\frac{\rho \alpha}{\beta}}\left\{\frac{1}{1-\beta}\right\}^{\frac{\rho \alpha}{\beta}} t^{\frac{\alpha}{\beta}}\left(\int_{o}^{a_{D}} a^{\frac{(1-\alpha)}{\beta}(1-\sigma)} d G+\phi(1+\phi)^{\frac{1-\beta}{\beta}} \int_{o}^{a_{X}} a^{\frac{(1-\alpha)}{\beta}(1-\sigma)} d G\right)^{\frac{1}{1-\sigma}} \\
P^{1-\sigma} & =n\left(\frac{\sigma}{\sigma-1} \kappa B^{-\frac{\rho \alpha}{\beta}}\left\{\frac{1}{1-\beta}\right\}^{\frac{\rho \alpha}{\beta}} t^{\frac{\alpha}{\beta}}\right)^{1-\sigma} a_{D}^{\frac{(1-\alpha)(1-\sigma)}{\beta}} \cdot \\
& \left(\frac{\beta k}{(1-\alpha)(1-\sigma)+\beta k}+\phi(1+\phi)^{\frac{1-\beta}{\beta}} \frac{\beta k}{(1-\alpha)(1-\sigma)+\beta k}\left(\frac{a_{X}}{a_{D}}\right)^{k+\frac{(1-\alpha)(1-\sigma)}{\beta}}\right)
\end{aligned}
$$

where we in turn can substitute in $a_{X} / a_{D}$ from (68) to get

$$
\begin{aligned}
P^{1-\sigma}= & n B^{-\frac{\rho \alpha(1-\sigma)}{\beta}}\left(\frac{\sigma}{\sigma-1} \kappa\left\{\frac{1}{1-\beta}\right\}^{\frac{\rho \alpha}{\beta}} t^{\frac{\alpha}{\beta}}\right)^{1-\sigma} a_{D}^{\frac{(1-\alpha)(1-\sigma)}{\beta}} . \\
& \frac{\beta k}{(1-\alpha)(1-\sigma)+\beta k}\left(1+\phi(1+\phi)^{\frac{1-\beta}{\beta}}\left(\left((\phi+1)^{\frac{1}{\beta}}-1\right) \frac{f_{D}}{f_{X}}\right)^{\frac{k \beta}{(1-\alpha)(\sigma-1)}-1}\right)
\end{aligned}
$$

Now we substitute in for $B(65)$

$$
\begin{aligned}
P^{1-\sigma} & =n a_{D}^{-(1-\alpha)(\sigma-1)} t^{-\alpha(\sigma-1)} f_{D}^{1-\beta} \varkappa^{\beta-1}\left(\frac{\sigma}{\sigma-1} \kappa\left\{\frac{1}{1-\beta}\right\}^{\frac{\rho \alpha}{\beta}}\right)^{1-\sigma} \cdot \\
& \frac{\beta k}{(1-\alpha)(1-\sigma)+\beta k}\left(1+\phi(1+\phi)^{\frac{1-\beta}{\beta}}\left(\left((\phi+1)^{\frac{1}{\beta}}-1\right) \frac{f_{D}}{f_{X}}\right)^{\frac{k \beta}{(1-\alpha)(\sigma-1)}-1}\right)
\end{aligned}
$$

From definition of $B$ and (65) $P_{j}^{1-\sigma}=\varsigma \mu L_{j} \varkappa^{\beta} f_{D}^{-\beta} a_{D}^{(1-\alpha)(1-\sigma)} t^{\alpha(1-\sigma)}$ which allows us to write: 


$$
\begin{aligned}
\varsigma \mu L_{j} \varkappa^{\beta} f_{D}^{-\beta} a_{D}^{(1-\alpha)(1-\sigma)} t^{\alpha(1-\sigma)} & =n a_{D}^{-(1-\alpha)(\sigma-1)} t^{-\alpha(\sigma-1)} f_{D}^{1-\beta} \varkappa^{\beta-1}\left(\frac{\sigma}{\sigma-1} \kappa\left\{\frac{1}{1-\beta}\right\}^{\frac{\rho \alpha}{\beta}}\right)^{1-\sigma} \cdot \\
& \frac{\beta k}{(1-\alpha)(1-\sigma)+\beta k}\left(1+\phi(1+\phi)^{\frac{1-\beta}{\beta}}\left(\left((\phi+1)^{\frac{1}{\beta}}-1\right) \frac{f_{D}}{f_{X}}\right)^{\frac{k \beta}{(1-\alpha)(\sigma-1)}-1}\right)
\end{aligned}
$$

with $\varsigma \equiv \kappa^{1-\sigma} \sigma^{-\sigma}(\sigma-1)^{\sigma-1}, \varkappa \equiv(1-\beta)^{\frac{1-\beta}{\beta}}-(1-\beta)^{\frac{1}{\beta}}$, and $\beta=1-\alpha \rho(\sigma-1)$, and to rewrite to get an expression for equilibrium number of firms

$$
n=\frac{\beta \mu L}{f_{D} \sigma \frac{\beta k}{(1-\alpha)(1-\sigma)+\beta k}\left(1+\phi(1+\phi)^{\frac{1-\beta}{\beta}}\left(\left((\phi+1)^{\frac{1}{\beta}}-1\right) \frac{f_{D}}{f_{X}}\right)^{\frac{k \beta}{(1-\alpha)(\sigma-1)}-1}\right)}
$$

\section{A.7.4 Non-exporter emissions}

Emission intensity is given by (from the main text):

$$
\frac{e}{x}=\alpha \kappa t^{\alpha-1} f_{A}^{-\rho \alpha} a^{1-\alpha}
$$

Substituting optimal abatement investments from (14)

$$
f_{A}^{D}=\left\{\frac{1}{B}\left(a^{1-\alpha} t^{\alpha}\right)^{\sigma-1} \frac{1}{\alpha \rho(\sigma-1)}\right\}^{\frac{1}{\alpha \rho(\sigma-1)-1}}
$$

gives

$$
e^{D}=\alpha \kappa t^{\frac{\alpha-\beta}{\beta}} B^{-\frac{\rho \alpha}{\beta}}\left(\frac{1}{1-\beta}\right)^{\frac{\rho \alpha}{\beta}} a^{\frac{(1-\alpha)}{\beta}} x
$$

First, derive the equilibrium emission intensity of non-exporters in the symmetric case. Substituting for $B$ from (65) gives

$$
e^{D}=\alpha \kappa t^{\frac{\alpha-\beta}{\beta}-\frac{\alpha(1-\beta)}{\beta}} f_{D}^{-\rho \alpha} \varkappa^{\rho \alpha} a_{D}^{-\frac{(1-\beta)}{\beta}(1-\alpha)}\left(\frac{1}{1-\beta}\right)^{\frac{\rho \alpha}{\beta}} a^{\frac{(1-\alpha)}{\beta}} x
$$

with $\varsigma \equiv \kappa^{1-\sigma} \sigma^{-\sigma}(\sigma-1)^{\sigma-1}, \varkappa \equiv(1-\beta)^{\frac{1-\beta}{\beta}}-(1-\beta)^{\frac{1}{\beta}}$, and $\beta=1-\alpha \rho(\sigma-1)$. We rewrite so that

$$
\frac{e^{D}}{x}=\alpha \kappa t^{\frac{\alpha-\beta}{\beta}-\frac{\alpha(1-\beta)}{\beta}} f_{D}^{-\rho \alpha} a_{D}^{-\frac{(1-\beta)}{\beta}(1-\alpha)}\left((1-\beta)^{\frac{1-\beta}{\beta}}-(1-\beta)^{\frac{1}{\beta}}\right)^{\rho \alpha}\left(\frac{1}{1-\beta}\right)^{\frac{\rho \alpha}{\beta}} a^{\frac{(1-\alpha)}{\beta}}
$$

and simplify to get

$$
\frac{\bar{e}^{D}}{x}=\alpha \kappa t^{\alpha-1} f_{D}^{-\rho \alpha} a_{D}^{-\frac{(1-\beta)}{\beta}(1-\alpha)}\left(\frac{\beta}{1-\beta}\right)^{\rho \alpha} a^{\frac{(1-\alpha)}{\beta}}
$$


For exporters we can calculate the equilibrium emission intensity in a similar fashion:

$$
\frac{\bar{e}^{X}}{x}=\alpha \kappa t^{\alpha-1} f_{D}^{-\rho \alpha}(1+\phi)^{-\frac{\rho \alpha}{\beta}} a_{D}^{-\frac{(1-\beta)}{\beta}(1-\alpha)}\left(\frac{\beta}{1-\beta}\right)^{\rho \alpha} a^{\frac{(1-\alpha)}{\beta}}
$$

Next, we calculate the level of total emissions. We start with non-exporters. The quantity sold domestically is:

$$
x=\frac{p^{-\sigma} \mu L}{P^{1-\sigma}}
$$

Non-export price

$p=\frac{\sigma}{\sigma-1} \kappa B^{-\frac{\rho \alpha}{\beta}}\left\{\frac{1}{1-\beta}\right\}^{\frac{\rho \alpha}{\beta}} t^{\frac{(1-\beta) \alpha}{\beta}+\alpha} a^{(1-\alpha)+\frac{(1-\alpha)(1-\beta)}{\beta}}=\frac{\sigma}{\sigma-1} \kappa B^{-\frac{\rho \alpha}{\beta}}\left\{\frac{1}{1-\beta}\right\}^{\frac{\rho \alpha}{\beta}} t^{\frac{\alpha}{\beta}} a^{\frac{(1-\alpha)}{\beta}}$

which gives

$$
x=\frac{\left(\frac{\sigma}{\sigma-1}\right)^{-\sigma} \kappa^{-\sigma} \mu L B^{\frac{\sigma \rho \alpha}{\beta}}\left(\left\{\frac{1}{1-\beta}\right\}^{\frac{\rho \alpha}{\beta}} t^{\frac{\alpha}{\beta}} a^{\frac{(1-\alpha)}{\beta}}\right)^{-\sigma}}{P^{1-\sigma}} .
$$

Since $B \equiv \frac{\kappa^{1-\sigma} \sigma^{-\sigma}(\sigma-1)^{\sigma-1} \mu L_{j}}{P_{j}^{1-\sigma}}$, this implies that $\frac{(\sigma-1) B}{\kappa}=\frac{\kappa^{-\sigma} \sigma^{-\sigma}(\sigma-1)^{\sigma} \mu L_{j}}{P_{j}^{1-\sigma}}$. which we can use to substitute into (83), to get

$$
x=\frac{(\sigma-1)}{\kappa} B^{\frac{\sigma \rho \alpha}{\beta}+1} t^{-\frac{\sigma \alpha}{\beta}} a^{-\frac{\sigma(1-\alpha)}{\beta}}\left\{\frac{1}{1-\beta}\right\}^{-\frac{\sigma \rho \alpha}{\beta}}
$$

which we in turn substitute into (80). This gives

$$
e^{D}=\alpha \kappa t^{\frac{\alpha-\beta}{\beta}} B^{-\frac{\rho \alpha}{\beta}}\left(\frac{1}{1-\beta}\right)^{\frac{\rho \alpha}{\beta}} a^{\frac{(1-\alpha)}{\beta}} \frac{(\sigma-1)}{\kappa} B^{\frac{\sigma \rho \alpha}{\beta}+1} t^{-\frac{\sigma \alpha}{\beta}} a^{-\frac{\sigma(1-\alpha)}{\beta}}\left\{\frac{1}{1-\beta}\right\}^{-\frac{\sigma \rho \alpha}{\beta}}
$$

which can be simplified to get

$$
e^{D}=\alpha t^{\frac{\alpha(1-\sigma)-\beta}{\beta}}\left(\frac{1}{1-\beta}\right)^{\frac{\beta-1}{\beta}} a^{\frac{(1-\alpha)(1-\sigma)}{\beta}}(\sigma-1) B^{\frac{1}{\beta}} .
$$

Total emissions of non-exporters are (from the main text):

$$
E_{D}=n \int_{a_{X}}^{a_{D}} e d G\left(a \mid a_{D}\right)
$$

Solving the integral, conditional on entry gives:

$$
E_{D}=n \alpha t^{\frac{\alpha(1-\sigma)-\beta}{\beta}}\left(\frac{1}{1-\beta}\right)^{\frac{\beta-1}{\beta}}(\sigma-1) B^{\frac{1}{\beta}} \frac{k \beta}{(1-\alpha)(1-\sigma)+k \beta} a_{D}^{-\frac{(1-\alpha)(\sigma-1)}{\beta}}\left(1-\left(\frac{a_{X}}{a_{D}}\right)^{-\frac{(1-\alpha)(\sigma-1)}{\beta}+k}\right)
$$


while from (68) we have that $a_{X} / a_{D}=\left((\phi+1)^{\frac{1}{\beta}}-1\right)^{\frac{\beta}{(1-\alpha)(\sigma-1)}} \frac{f_{D}^{\frac{\beta}{(1-\alpha)(\sigma-1)}}}{f_{X}^{\overline{(1-\alpha)(\sigma-1)}}}$. Substitute this and $n$ from (79) gives

$$
\begin{aligned}
E_{D}= & \frac{\beta \mu L(\sigma-1) B^{\frac{1}{\beta}}}{f_{D} \sigma \frac{\beta k}{(1-\alpha)(1-\sigma)+\beta k}\left(1+\phi(1+\phi)^{\frac{1-\beta}{\beta}}\left(\left((\phi+1)^{\frac{1}{\beta}}-1\right) \frac{f_{D}}{f_{X}}\right)^{\frac{k \beta}{(1-\alpha)(\sigma-1)}-1}\right)} \alpha t^{\frac{\alpha(1-\sigma)-\beta}{\beta}}\left(\frac{1}{1-\beta}\right)^{\frac{\beta-1}{\beta}} \\
& \cdot \frac{k \beta}{(1-\alpha)(1-\sigma)+k \beta} a_{D}^{-\frac{(1-\alpha)(\sigma-1)}{\beta}}\left(1-\left(\left((\phi+1)^{\frac{1}{\beta}}-1\right)^{\frac{\beta}{(1-\alpha)(\sigma-1)}} \frac{f_{D}^{\frac{\beta}{(1-\alpha)(\sigma-1)}}}{f_{X}^{\frac{\beta}{(1-\alpha)(\sigma-1)}}}\right)^{-\frac{(1-\alpha)(\sigma-1)}{\beta}+k}\right)
\end{aligned}
$$

We use (65) to substitute for $B$ and simplify to get

$$
\bar{E}_{D}=\frac{\left(1-\left(\left((\phi+1)^{\frac{1}{\beta}}-1\right) \frac{f_{D}}{f_{X}}\right)^{\frac{k \beta}{(1-\alpha)(\sigma-1)}-1}\right)}{\left(1+\phi(1+\phi)^{\frac{1-\beta}{\beta}}\left(\left((\phi+1)^{\frac{1}{\beta}}-1\right) \frac{f_{D}}{f_{X}}\right)^{\frac{k \beta}{(1-\alpha)(\sigma-1)}-1}\right)} \mu L \alpha t^{-1} \frac{(\sigma-1)}{\sigma}
$$

\section{A.7.5 Exporter emissions}

Next we turn to the emissions of exporters. From the main text we have that:

$$
e^{X}=\alpha \kappa t^{\frac{\alpha-\beta}{\beta}}(1+\phi)^{-\frac{\rho \alpha}{\beta}} \bar{B}^{-\frac{\rho \alpha}{\beta}}\left(\frac{1}{1-\beta}\right)^{\frac{\rho \alpha}{\beta}} a^{\frac{1-\alpha}{\beta}} x
$$

where

$$
x=(1+\phi) \frac{p^{-\sigma} \mu L}{P^{1-\sigma}}
$$

Substituting (15) gives the exporter price

$$
p=\frac{\sigma}{\sigma-1} \kappa(1+\phi)^{-\frac{\rho \alpha}{\beta}} B^{-\frac{\rho \alpha}{\beta}}\left\{\frac{1}{1-\beta}\right\}^{\frac{\rho \alpha}{\beta}} t^{\frac{\alpha}{\beta}} a^{\frac{(1-\alpha)}{\beta}}
$$

and substituting this into (88) gives

$$
x=(1+\phi) \frac{\left(\frac{\sigma}{\sigma-1}\right)^{-\sigma} \kappa^{-\sigma} \mu L(1+\phi)^{\frac{\sigma \rho \alpha}{\beta}} B^{\frac{\sigma \rho \alpha}{\beta}}\left(\left\{\frac{1}{1-\beta}\right\}^{\frac{\rho \alpha}{\beta}} t^{\frac{\alpha}{\beta}} a^{\frac{(1-\alpha)}{\beta}}\right)^{-\sigma}}{P^{1-\sigma}}
$$

We have that $B \equiv \frac{\kappa^{1-\sigma} \sigma^{-\sigma}(\sigma-1)^{\sigma-1} \mu L_{j}}{P_{j}^{1-\sigma}}$, which implies that $\frac{(\sigma-1) B}{\kappa}=\frac{\kappa^{-\sigma} \sigma^{-\sigma}(\sigma-1)^{\sigma} \mu L_{j}}{P_{j}^{1-\sigma}}$, which 
we substitute into (89) to get

$$
x=\frac{(\sigma-1)}{\kappa}(1+\phi)^{1+\frac{\sigma \rho \alpha}{\beta}} B^{\frac{\sigma \rho \alpha}{\beta}+1} t^{-\frac{\sigma \alpha}{\beta}} a^{-\frac{\sigma(1-\alpha)}{\beta}}\left\{\frac{1}{1-\beta}\right\}^{-\frac{\sigma \rho \alpha}{\beta}},
$$

and this in turn into (87) gives $\bar{e}^{X}$ :

$$
\bar{e}^{X}=\alpha t^{\frac{\alpha(1-\sigma)-\beta}{\beta}}\left(\frac{1}{1-\beta}\right)^{\frac{\beta-1}{\beta}} a^{\frac{(1-\alpha)(1-\sigma)}{\beta}}(\sigma-1)(1+\phi)^{\frac{1}{\beta}} B^{\frac{1}{\beta}}
$$

Now calculate total emissions from all exporters using that

$$
E_{X}=n \int_{0}^{a_{X}} e d G\left(a \mid a_{D}\right)
$$

We solve the integral and substitute in $\left(a_{X} / a_{D}\right)^{k}$ from (68):

$$
\begin{gathered}
E_{X}=n \alpha t^{\frac{\alpha(1-\sigma)-\beta}{\beta}}\left(\frac{1}{1-\beta}\right)^{\frac{\beta-1}{\beta}}(\sigma-1)(1+\phi)^{\frac{1}{\beta}}(B)^{\frac{1}{\beta}} \frac{k \beta}{(1-\alpha)(1-\sigma)+k \beta} \\
\left(\left((\phi+1)^{\frac{1}{\beta}}-1\right)^{\frac{k \beta}{(1-\alpha)(\sigma-1)}} \frac{f_{D}^{\frac{k \beta}{(1-\alpha)(\sigma-1)}}}{f_{X}^{\frac{k \beta}{(1-\alpha)(\sigma-1)}}}\right) a_{X}^{\frac{(1-\alpha)(1-\sigma)}{\beta}},
\end{gathered}
$$

subsitute $B=\frac{a_{X}^{(1-\alpha)(\sigma-1)} t^{\alpha(\sigma-1)} f_{X}^{\beta}}{\left((1+\phi)^{\frac{1}{\beta}}-1\right)^{\beta} \varkappa^{\beta}}$ from $(67)$ :

$$
\begin{aligned}
E_{X} & =n \alpha t^{-1}\left(\frac{1}{1-\beta}\right)^{\frac{\beta-1}{\beta}}(\sigma-1)(1+\phi)^{\frac{1}{\beta}} \frac{f_{X}}{\left((1+\phi)^{\frac{1}{\beta}}-1\right) \varkappa} \frac{k \beta}{(1-\alpha)(1-\sigma)+k \beta} . \\
& \left(\left((\phi+1)^{\frac{1}{\beta}}-1\right)^{\frac{k \beta}{(1-\alpha)(\sigma-1)}} \frac{f_{D}^{\frac{k \beta}{(1-\alpha)(\sigma-1)}}}{f_{X}^{\frac{k \beta}{(1-\alpha)(\sigma-1)}}}\right)
\end{aligned}
$$

then we substitute in $n$ from $(79)$ and use that $\varkappa=(1-\beta)^{\frac{1-\beta}{\beta}}-\{1-\beta\}^{\frac{1}{\beta}}$, which after simplifying gives us

$\bar{E}_{X}=\frac{\left(\frac{f_{D}}{f_{X}}\right)^{\frac{k \beta}{(1-\alpha)(\sigma-1)}}}{\sigma\left((1+\phi)^{-\frac{1}{\beta}}\left((1+\phi)^{\frac{1}{\beta}}-1\right)^{1-\frac{k \beta}{(1-\alpha)(\sigma-1)}}+\frac{\phi}{(1+\phi)}\left(\frac{f_{D}}{f_{X}}\right)^{\frac{k \beta}{(1-\alpha)(\sigma-1)}-1}\right)} \alpha t^{-1}(\sigma-1) \frac{f_{X}}{f_{D}} \mu L$ 


\section{A.7.6 Total emisssions}

We have from (86) that:

$$
\bar{E}_{D}=\frac{\left(1-\left(\left((\phi+1)^{\frac{1}{\beta}}-1\right) \frac{f_{D}}{f_{X}}\right)^{\frac{k \beta}{(1-\alpha)(\sigma-1)}-1}\right)}{\left(1+\phi(1+\phi)^{\frac{1-\beta}{\beta}}\left(\left((\phi+1)^{\frac{1}{\beta}}-1\right) \frac{f_{D}}{f_{X}}\right)^{\frac{k \beta}{(1-\alpha)(\sigma-1)}-1}\right)} \mu L \alpha t^{-1} \frac{(\sigma-1)}{\sigma}
$$

Using this and $\bar{E}_{X}$ from (90) gives total emissions

$$
\begin{aligned}
& E_{t o t}=E_{D}+E_{X}=\frac{\left(1-\left(\left((\phi+1)^{\frac{1}{\beta}}-1\right) \frac{f_{D}}{f_{X}}\right)^{\frac{k \beta}{(1-\alpha)(\sigma-1)}-1}\right)}{\left(1+\phi(1+\phi)^{\frac{1-\beta}{\beta}}\left(\left((\phi+1)^{\frac{1}{\beta}}-1\right) \frac{f_{D}}{f_{X}}\right)^{\frac{k \beta}{(1-\alpha)(\sigma-1)}-1}\right)} \mu L \alpha t^{-1} \frac{(\sigma-1)}{\sigma}+
\end{aligned}
$$

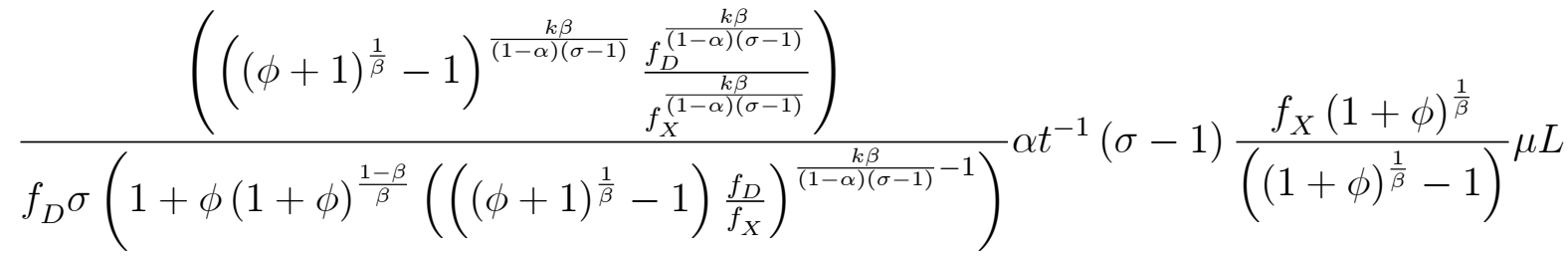

which can be simplified to be expressed by

$$
\bar{E}_{t o t}=\mu L \alpha t^{-1} \frac{(\sigma-1)}{\sigma}\left(\frac{1+\left((1+\phi)^{\frac{1}{\beta}}-1\right)\left(\left((\phi+1)^{\frac{1}{\beta}}-1\right) \frac{f_{D}}{\left.f_{X}\right)^{\frac{k \beta}{(1-\alpha)(\sigma-1)}-1}}\right.}{1+\frac{\phi}{(1+\phi)}(1+\phi)^{\frac{1}{\beta}}\left(\left((\phi+1)^{\frac{1}{\beta}}-1\right) \frac{f_{D}}{f_{X}}\right)^{\frac{k \beta}{(1-\alpha)(\sigma-1)}-1}}\right)
$$

